\title{
Metaheuristics for agricultural land use optimization. A review
}

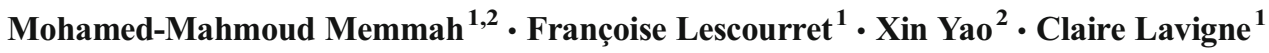

Accepted: 24 March 2015 / Published online: 21 May 2015

(C) INRA and Springer-Verlag France 2015

\begin{abstract}
Agricultural landscapes presently cover about $46 \%$ of earth terrestrial surface. This cultivated area is decreasing, whereas the global food demand is projected to increase up to $70 \%$ in 2050 . The intensification of agriculture is not a solution to this food issue because intensive agriculture has often resulted in pollution and loss of biodiversity. On the other hand, mechanistic models with optimization algorithms can be used to design alternative land uses for sustainable agriculture. Here, we present a review of metaheuristics for land use optimization reported in 50 articles including 38 case studies carried out in 16 countries. Our main conclusions are: 1) the success of metaheuristics is problem-dependent. In general, metaheuristics enable search to escape from local optima and find a good global approximation solution. 2) The choice of a given metaheuristic for solving a given problem seems to be driven by its historical use in a research team and by its popularity outside the metaheuristics research community, rather than by the characteristics of the problems to be solved and by the latest results from the metaheuristics research community. 3) Stakeholders of land use are increasingly involved
\end{abstract}

Mohamed-Mahmoud Memmah

mmouldsidi@paca.inra.fr

Françoise Lescourret

francoise.lescourret@paca.inra.fr

Xin Yao

x.yao@cs.bham.ac.uk

Claire Lavigne

claire.lavigne@paca.inra.fr

1 INRA, UR1115, Plantes et Systèmes de culture Horticoles, 84000 Avignon, France

2 The Centre of Excellence for Research in Computational Intelligence and Applications (CERCIA), School of Computer Science, The University of Birmingham, Edgbaston, Birmingham B15 2TT, UK at different levels of the land use optimization procedure and multi-actors decision-making methods are necessary to find trade-offs between their competing interests. 4) A future challenge is the use of parallelization techniques along with the hybridization of different metaheuristics or of metaheuristics with other optimization methods.

Keywords Agricultural land use optimization · Metaheuristics $\cdot$ Multifunctional agriculture $\cdot$ Economic crop planning $\cdot$ Water resources management $\cdot$ Nature conservation $\cdot$ Forest management $\cdot$ Interactive decision-making

Contents

1 Introduction

2 Metaheuristics

2.1 Definitions

2.2 Basic concepts

2.3 Reasons of metaheuristics success

2.4 Examples

3. Land use optimization using metaheuristics

3.1 Economic crop planning

3.2 Water resources management

3.3 Nature conservation in landscapes

3.4 Multifunctional agricultural landscapes

4. Discussion

4.1 Impact of the history of research communities

4.2 An increasing number of objectives and constraints: scalability of metaheuristics

4.3 Which metaheuristic for which problem?

4.4 Balancing the trade-off between exploration and exploitation: Hybridization

4.5 Adapting computational facilities to handle a large number of decision variables and dynamics 
4.6 Decision-making issues: Integrating the knowledge of decision-makers

4.7 Methodological studies for different land use optimization problems

5. Conclusion

Acknowledgments

References

\section{Introduction}

Agricultural landscapes, covering roughly $46 \%$ of the earth terrestrial surface, are facing a challenge to meet the global food requirements expected to increase by as much as $70 \%$ by 2050 (Hooke et al. 2012; Barral et al. 2015). Agricultural systems are nowadays considered as one of the major sources of environmental pollution and deterioration of biodiversity features worldwide, including species extinction (Münier et al. 2004; Sarkar et al. 2006). However, agroecosystems have the potential to deliver many regulation ecosystem services such as pest regulation, water cleaning, or carbon sequestration. In this context, decision-makers and stakeholders are facing the challenge to identify alternative management options and practices reducing the reliance of agriculture on external chemical inputs, especially pesticides, and promoting these services. Land use management could help to deal with such a challenge and to reconcile viability of agricultural systems, environment protection, and biodiversity preservation (Fig. 1) (Taki et al. 2013). It has been shown, for example, that improper land management might disserve the biological control of pests (Taki et al. 2013) and lead to pollution due to fertilizers and pesticides (Zhang et al. 2013).

Land use spatial allocation is defined by many authors as the process of assigning different uses (industrial zones, agricultural areas, recreation zones, public facilities) to specific geographical zones in order to optimize the spatial and temporal efficiency of land use (Stewart et al. 2004; Liu et al. 2013c). The land use allocation problem covers a large number of domains, e.g., urban and regional planning, facility locations, land acquisition, reserves and forest management, and crop allocation (Ligmann-Zielinska et al. 2005). Agricultural land use allocation, which is a particular case of land use allocation, consists of allocating different species and activities to different areas in agricultural landscapes (Liu et al. 2013c; Stewart et al. 2004). This type of allocation can be dealt with by a model-based design approach relying on land use models and optimization techniques. The advantage of this approach is to allow decision-makers to explore a large number of land use combinations. Agricultural land use optimization is a very hard and complex task involving many stakeholders and decision-makers, many spatial factors, attributes and constraints, and multiple conflicting objectives (Liu et al. 2013c). In addition, temporal constraints such as crop rotations and land rent duration have to be taken into account. The design of agricultural land use scenarios has been studied as a multi-objective optimization problem involving conflicting environmental, e.g., insecticides use reduction, economical, e.g., farmer's income, and technical, e.g., regrouping the same land uses in patches, objectives. The optimization techniques are widely considered as very useful for model-based land use allocation and management. Two main classes of
Fig. 1 French multifunctional landscapes. a Common cranes feeding in the remnants of a maize field close to a pine forest (Landes); b grassland next to fern vegetation traditionally used for sheep bedding (Pyrénées); c residential buildings built on former agricultural land (Ile de France)

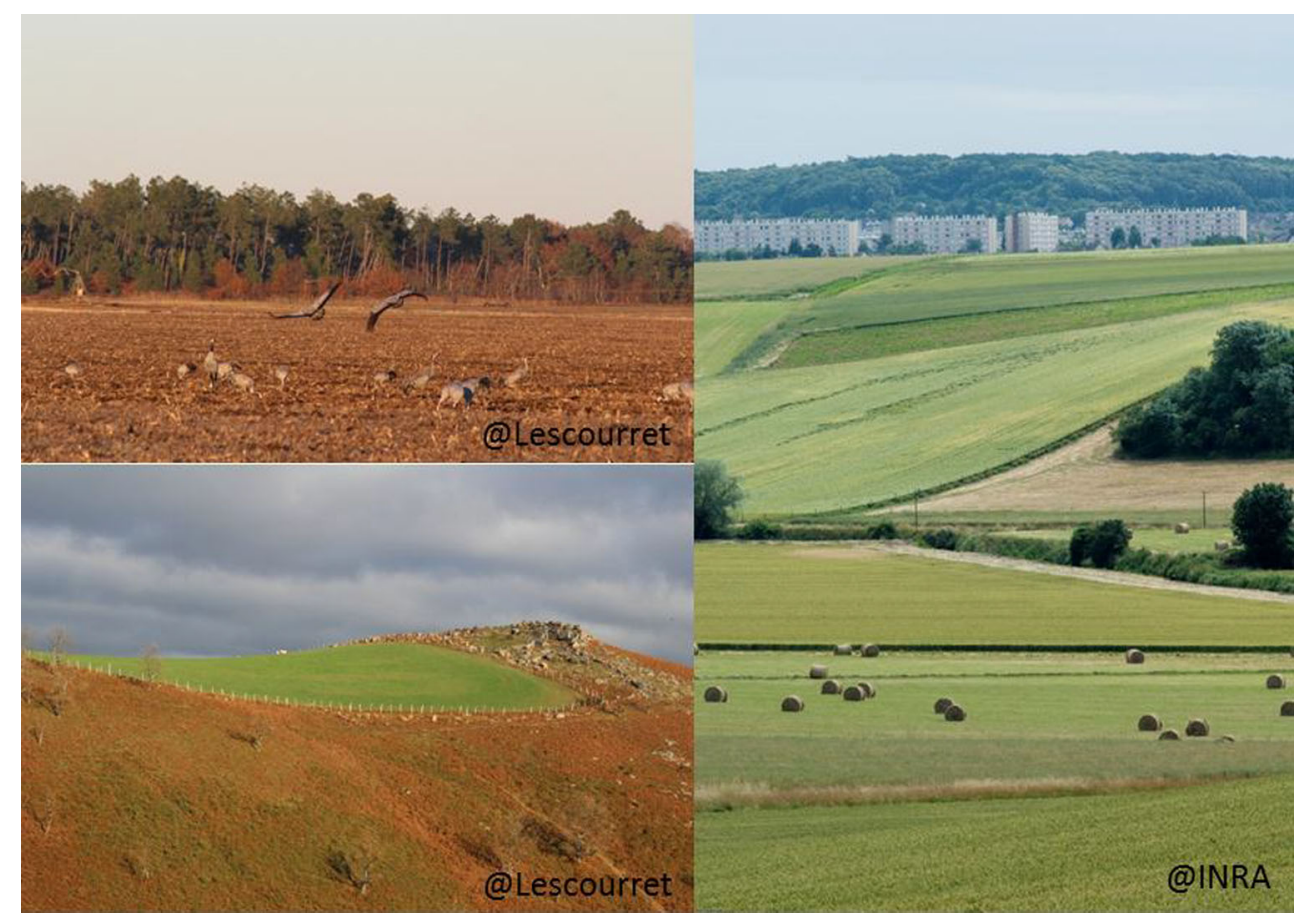


optimization approaches could be distinguished: deterministic and stochastic.

The majority of the traditional optimization methods are based on deterministic approaches. Examples include the simplex method for linear programming, gradient-based methods, e.g., the Newton-Raphson algorithm, and gradient-free methods such as Hooke-Jeeves and Nelder-Mead algorithms (Yang 2011; Cordon et al. 2002; Lin et al. 2012). Methods such as dynamic programming, backtracking, and branchand-bound methods are other examples of deterministic methods dedicated to the exact resolution of some problems (Bahesti and Shamsuddin 2013; Cordon et al. 2002).

Such classical mathematical programming methods were among the first used approaches for land use optimization. Many studies using linear programming solvers for land use optimization have been published. These studies dealt with problems involving one single objective as well as multiple objectives through the use of aggregation methods, in which different objectives are synthesized in one value that needs to be optimized (Stewart et al. 2004).

Some studies of agricultural land use allocation based on classical mathematical approaches were dealing with agroecological and socioeconomic aspects of production (Van Huylenbroeck 1997; Sarttra et al. 2013; Raggi et al. 2013; Min et al. 2010; Gabriel et al. 2006; Campbell et al. 1992; Domptail and Nuppenau 2010; El Sayed Abdel Asís 2007; Alabdulkader et al. 2012; Wankhade and Lunge 2012; de Figueiredo et al. 2012; Akplogan et al. 2011). Others were dedicated to watersheds and water resources management (Klein et al. 2013; Zhang et al. 2013; Walangitan et al. 2012; Wang et al. 2004; Sadeghi et al. 2009; Gärtner et al. 2013; Gao et al. 2010; Cotter et al. 2014; Meyer et al. 2012; Aerts et al. 2003a; Dai and Li 2013). Another aspect of those studies is landscape ecology, including the impact of agricultural landscape structure, landscape elements configuration and forest management on species distribution, habitat quality and suitability improvement, and nature conservation and restoration (Zhang et al. 2014; Wang et al. 2012; van Langevelde et al. 2002; Store and Kangas 2001; Prato 2005; Orsi et al. 2011; Münier et al. 2004; Chuai et al. 2013; Brooker 2002; Bamière et al. 2011; O'Callaghan 1995; Wossink et al. 1999). Energy and carbon storage issues have also been considered in some of those studies (Callesen et al. 2010).

Although deterministic approaches have been used successfully and have good performance in some cases, they show poor performances for many problems. Their drawbacks include their inefficiency to deal with large-scale combinatorial and highly nonlinear optimization problems. Indeed, no exhaustive search is possible for problems of large size since the size of the search space often increases exponentially as the number of problem dimension grows. Some mathematical properties (e.g., smoothness, unimodality) of problems required by gradient-based methods may not be satisfied for some land use optimization problems (Bahesti and Shamsuddin 2013).

The use of mathematical programming techniques for land use optimization has some limitations despite successful applications reported in the literature. As pointed out by Stewart et al. (2004), four limitations create the need for more effective optimization algorithms for agricultural land used allocation. The first limitation concerns the efficiency of such approaches to tackle problems involving large geographical areas and high resolution due to the very high number of integer variables induced in such a case. Despite the advance in developing powerful solvers and the computers' speed explosion, mathematical programming techniques are still struggling to deal with problems involving a large number of variables. The second limitation is related to the difficulty of mathematical programming techniques to deal with problems involving a large number of nonlinear objectives and constraints as it is the case usually in land use optimization. Indeed, these approaches require strict mathematically defined objectives and constraints which are usually impossible to obtain in the case of land use models, especially if they take into account different processes (biological, physical). This limitation is due to the increasing complexity of the land use problems. The third limitation is the need to take into account the points of view of many stakeholders and decision-makers increasingly involved in the process of land use allocation. Such diversity of points of view with different priorities is better reflected by a set of solutions than by a single "optimal" solution. We thus need algorithms able to generate a relevant set of trade-off solutions reflecting the preferences of each stakeholder involved in the process. Similarly, the involvement of more and more decision-makers and the need for interactive decision-support systems requires faster algorithms (short computational time) to allow for realtime interaction (Stewart et al. 2004).

Stochastic approaches are considered as more flexible and efficient to tackle large and complex optimization problems that are non-differentiable, multimodal, and multi-objective. Two main types of stochastic approaches could be distinguished: heuristics including construction algorithms and local search algorithms and metaheuristics. Heuristics do not guarantee the optimality of the solution, but they can be used to find good approximate solutions in a reasonable computational time. Construction algorithms find a near-optimal solution by adding solution components step by step. Although construction algorithms are known to be very fast compared to exact methods (dynamic programming), they make very strong assumptions in many situations, and the optimality of their solutions is very sensitive even to small changes in the construction process (Cordon et al. 2002). Local search algorithms rely on the iterative improvement of the current solution by visiting its neighbors. If a better solution is identified, it becomes the current solution; else the current solution is kept. Local search may be trapped in a local optimum. The 
main drawback of local search algorithms is thus their susceptibility to poor quality local optima. Heuristics are usually problem specific since they use information from the problem at hand to guide search, which implies the need for a new heuristic for every new problem.

The development of metaheuristics algorithms was motivated by two limitations: to escape from local optima and to have more general-purpose algorithms. Metaheuristics do not assume any mathematical property of the treated problem and can deal with multiple points of view of stakeholders in a reasonable amount of computation time. Metaheuristics, such as genetic algorithms (Cao et al. 2011; Stewart et al. 2004), simulated annealing (Duh and Brown 2007; Santé-Riveira et al. 2008), particle swarm optimization (Liu et al. 2013a; Masoomi et al. 2012), and ant colony optimization (Yu et al. 2011; Mousa and El_Desoky 2013), combined with multiobjective optimization techniques can generate diversified land use planning scenarios (more details below). These approaches are efficient for solving land use spatial allocation problems.

In the next section, we present some basic concepts of metaheuristics and give examples of the most used classes of these approaches. Then, in section 3, we review the use of such approaches for agricultural land use optimization. Section 4 is dedicated to the discussion of advantages and limitations of using metaheuristics for agricultural land use. The last section concludes the paper and gives some perspectives.

\section{Metaheuristics}

Land use allocation is very complex and hard to solve in practice. The efficiency and efficacy of the proposed optimization algorithms have been considerably improved over the years to tackle such difficult problems. Metaheuristics are among the most suitable approaches for solving such hard combinatorial and nonlinear global optimization problems (Ólafsson S 2006; Wetter and Wright 2004).

\subsection{Definitions}

Although metaheuristics are very successful and well known, there is no universal definition commonly agreed for this term. Consequently, many definitions of metaheuristics are reported in the literature. Some emphasize their ability to control the use of lower-level heuristics: Laporte and Osman (1995), cited by Bahesti and Shamsuddin (2013), suggested to define a metaheuristic as "An iterative generation process which guides a subordinate heuristic by combining intelligently different concepts for exploring and exploiting the search space using learning strategies to structure information in order to find efficiently near-optimal solutions" (Laporte and Osman
1995). Another definition, also cited in (Bahesti and Shamsuddin 2013), was proposed by Voss et al. (1999): “an iterative master process that guides and modifies the operations of subordinate heuristics to efficiently produce highquality solutions. It may manipulate a complete (or incomplete) single solution or a collection of solutions per iteration. The subordinate heuristics may be high (or low) level procedures, or a simple local search, or just a construction method" (Voss et al. 1999).

Other definitions refer to the ability of metaheuristics to adapt to a large set of problems. According to Blum et al. (2011), "the term of metaheuristics generally refers to approximate algorithms for optimization that are not specifically expressed for a particular problem" (Blum et al. 2011). Following Boussaid et al. (2013), "A metaheuristics is an algorithm designed to solve approximately a wide range of hard optimization problems without having to deeply adapt to each problem" (Boussaï et al. 2013). Therefore, roughly speaking, we can consider metaheuristic as any high level heuristic that is easily adaptable for solving a large number of optimization problems.

\subsection{Basic concepts}

Metaheuristics usually assume no mathematical information (e.g., first or second derivatives) on the considered problem but require appropriate setting of some parameters (Boussaïd et al. 2013; Bahesti and Shamsuddin 2013). A large number of metaheuristics have been developed during the past few decades. Examples of metaheuristics, given in historical order, include Genetic Algorithms (Holland 1975), Simulated Annealing (Kirkpatrick et al. 1983), Artificial Immune Systems (Farmer et al. 1986), Taboo Search (Glover 1989, 1990), Ant Colony Optimization (Dorigo et al. 1991), Particle Swarm Optimization (Kennedy and Eberhart 1995), Differential Evolution (Storn and Price 1997), etc. (Bahesti and Shamsuddin 2013; Boussaïd et al. 2013).

These algorithms could be classified into many categories. For example, we could distinguish nature-inspired from nonnature-inspired metaheuristics, population-based from singlesolution based metaheuristics, metaheuristics considering single neighborhood from those considering various neighborhoods structures and those with memory usage from memory-less methods (Bahesti and Shamsuddin 2013). According to Boussaïd et al. (2013), classification differentiating single solution-based and population-based metaheuristics is the most common in the literature.

\subsection{Reasons of metaheuristics success}

Many reasons are cited to explain the success of metaheuristics. First, the use of stochastic operators allows metaheuristics to escape from local optima and converge to 
approximate global optima. The idea here is not to find the exact optimal solution of the problem at hand but to find solution(s) of good quality within a reasonable computational time. The key element in order to achieve such an objective relies on the suitable trade-off between exploration and exploitation. Exploration aims to identify the most promising regions in a search space through the diversification of search directions. Then, exploitation locally intensifies the search in a promising region to find solutions of high quality. The better a given metaheuristic performs in balancing these two operations, the better its performance will be (Boussaïd et al. 2013). The existing metaheuristics achieve the balance between these two operations differently. They might be more adapted for exploration or for exploitation. Hybrid metaheuristics combine two or more algorithms to take advantages from each while avoiding as much as possible their drawbacks (Boussaïd et al. 2013). Second, the availability of powerful computational resources (clouds, clusters) and the development of parallel architectures have considerably contributed to the success story of metaheuristics by reducing the computational time, which is one of their weak points (Boussaïd et al. 2013). The third reason for the success metaheuristics is due to their generality and ease to use and tune in practice.

\subsection{Examples}

The most used metaheuristics in agricultural land use optimization, as observed from our review, are simulated annealing, taboo search, evolutionary algorithms, differential evolution, particle swarm optimization, and ant colony optimization. The main ideas and basic concepts of these metaheuristics are presented in the following paragraphs.

Simulated annealing (Kirkpatrick et al. 1983): is a global optimization method originated from statistical mechanics by emulating physical processes. The annealing technique tries to slowly decrease the temperature of an initially heated material in order to eventually avoid the appearance of defects so that the frozen state occurs at the minimum energy configuration. Using the temperature as a parameter, the simulated annealing algorithm makes the parallel between the defects and local optima on one hand and between the objective function and the energy of the solid on the other hand. Starting from an initial solution and an initial temperature, simulated annealing selects randomly a new solution from the neighborhood of the current solution. If the new solution improves the objective function, then this solution is accepted as the new current solution. Otherwise, the new solution could be accepted with a probability depending on the current and new values of objective function and on the temperature. This probability decreases with the temperature so that at the earlier search stages, the deteriorating moves are highly probable. The process is repeated until a stopping criterion is satisfied.

Taboo search (Fred Glover 1989): is a global optimization algorithm that uses "a meta-heuristic superimposed on another heuristic". Taboo search uses a local search or neighborhood process and enhances its performance by using mechanisms inspired from human memory, which avoids visiting recently visited solutions. To do so, the recent moves are stored in one or more taboo list(s). The use of taboo list ensures that new regions of search space will be visited and hopefully to find the global optimal solution by avoiding local ones.

Evolutionary algorithms (Yao and Xu 2006): include genetic algorithms, evolution strategies, evolutionary programming, and genetic programming. Their basic and common idea is to simulate the evolution of a population of potential solutions using operators such as selection, crossover, and mutation in order to create better individuals. An evolutionary algorithm starts from an initial population of solutions. At each generation, the algorithm selects, using an appropriate operator, a group of solutions (parents) and then uses recombination to create new individuals (offspring) and applies mutation to maintain the diversity in a population and finally selects among the combined parents and offspring populations the solutions forming the next generation (Fig. 2a). The selection is based on individual (solution) fitness which evaluates how good the solutions are according to the criteria of the problem. The process is repeated until the satisfaction of a predefined stopping criterion, such as the maximum number of generations.

Differential evolution (Storn and Price 1997): is a population-based metaheuristic, considered as a variant of evolutionary algorithms. Differential evolution starts from an initial population of solutions randomly generated or obtained by others means. At each generation, the algorithm applies mutation, crossover, and selection operators to the current population to create the next generation. First, the differential evolution generates a trial population containing the counterpart of each solution in the current population. To do so, a mutant solution of each individual in the current population is created often by adding a weighted difference of two other randomly selected solutions. This mutant individual is then used to create a trial solution by applying a crossover operator. The trial solution is finally compared to the target solution to select the best one of them, which will be retained for the next generation. The process is repeated until the stopping criterion is met.

Particle Swarm optimization (Eberhart and Kennedy 1995): is a population-based search algorithm inspired by social behaviors of bird flocking. Each individual in 
Fig. 2 a A sketch of an evolutionary algorithm. b The main steps of a particle swarm optimization algorithm a

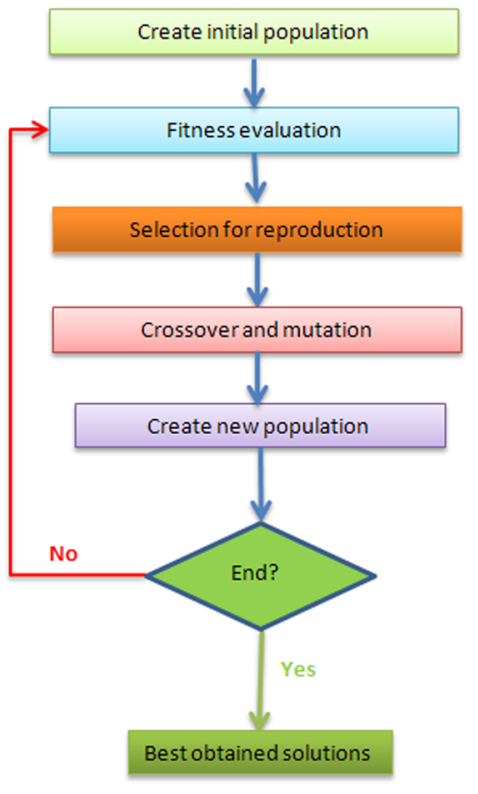

b

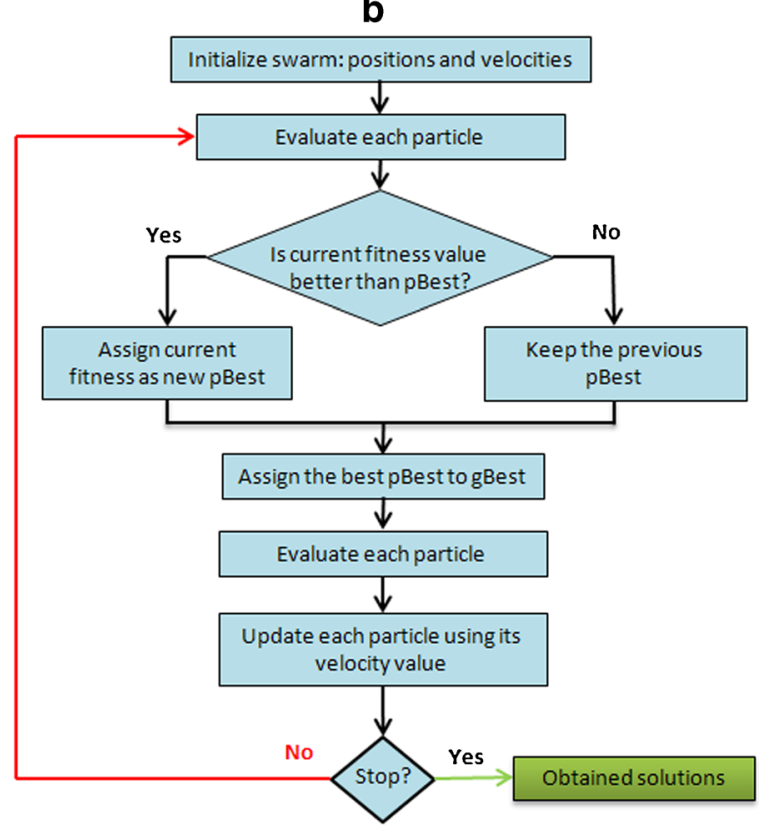

particle swarm optimization is referred to as a particle and represents a candidate solution to the optimization problem at hand. Each particle in particle swarm optimization flies through the search space with an adaptable velocity that is dynamically modified according to its own flying experience and also to the flying experience of the other particles. In particle swarm optimization, each particle tries to improve itself by imitating traits from their successful peers. Further, each particle has a memory, and hence it is capable of remembering the best position in the search space that it ever visited. The position corresponding to the best fitness of a given particle is known as "pbest" and the position corresponding to the best fitness over all the particles in the population is called "gbest" (Fig. 2b).

Ant colony optimization (Dorigo et al. 1991): is a natureinspired metaheuristic imitating the behavior of realworld ants' colonies in their search for food. The basic idea of ant colonies algorithms is to mimic the ants random walking on the graph representing the optimization problem to solve. The ant colonies are considered as construction algorithms as every ant constructs a solution by investigating the graph. The algorithm initiates a set of parameters and pheromone variables. Then, it constructs a colony of ants that concurrently move through the neighborhood of the states of the problem's construction graph. These moves are guided by a stochastic local decision strategy using pheromone trails and heuristic information. Once the solutions are constructed, the algorithm modifies the pheromone trails by updating, i.e., increasing or decreasing, the pheromone deposit to take into account the evaporation phenomenon and the ants' choice of some promising paths. The final step of the algorithm is the implementation of "centralized actions which cannot be performed by single ants" (daemon actions). The use of local search to improve the constructed solutions is an example of daemon actions.

In summary, there is high diversity of metaheuristics available in the literature. The balance of their exploitation and exploration abilities is one the most important keys to choose a suitable metaheuristic for a given optimization problem. The specific characteristics of the latter, e.g., the number of objectives and constraints could also guide this choice. Many literature reviews describing the historical development of metaheuristics and their basic concepts have been published (Bahesti and Shamsuddin 2013; Blum et al. 2011; Boussaïd et al. 2013; Jarraya and Bouri 2012; Jones et al. 2002; Madhuri and Deep 2009). We refer interested readers to the recent review of metaheuristics (Boussaïd et al. 2013).

\section{Land use optimization using metaheuristics}

This section reviews agricultural land use optimization using metaheuristics, following the contexts and the aims of studies. Inspired by the classification made in (Groot et al. 2007), we distinguished studies dealing with economic crop planning, water resources management issues, landscape ecology issues including forest management, and nature restoration (Groot et al. 2007; Badarudin et al. 2009). Many classifications of the studies dealing with land use allocation are possible following the used method, e.g., simulated annealing, taboo search, evolutionary algorithms, the type of decisions to be 
implemented, i.e., land use allocation to crops, configuration of the landscape, or combination of allocation and configuration, and the spatiotemporal decision levels, i.e., operational, tactical, strategic. Some of these classifications were used to structure the subsections and thus to facilitate reading of this paper. Figure 3 illustrates the use of metaheuristics in agricultural land use optimization.

\subsection{Economic crop planning}

This first part is dedicated to studies that used metaheuristics for agricultural land use optimization with special focus on economic crop planning. Although these studies take into account, to some extent, some ecological issues, their main contributions are more related to the agro and socioeconomic dimensions. Here, the criteria to be optimized are mostly farmer's income from harvest, type and amount of employment, biodiversity indices based on landscape ecological measures, diversity of land uses, soil erosion, and labor productivity. The metaheuristics used in this category are mainly simulated annealing, taboo search, ant colonies, evolutionary algorithms, and differential evolution. Examples of studies dealing with economic crop planning using these metaheuristics are presented hereafter according to the used method.

\subsubsection{Studies using simulated annealing}

A first set of studies used simulated annealing. These three studies have the common characteristics that they had few (i.e., no more than 3) criteria, often aggregated into one objective. They dealt with a low number of crops and land covers (10 roughly speaking). They included some methodological aspects by comparing different optimization methods.

The aim of the first study was to allocate six land use categories into a territory comprising five villages according to the constraints and needs of each category and to the global needs of the farming system (Le Ber et al. 1999). The used model was defined at the village scale. The objective function took into account production goals, their equilibrium (viability), and the constraints violation translated into penalties. Authors compared the simulated annealing results with those

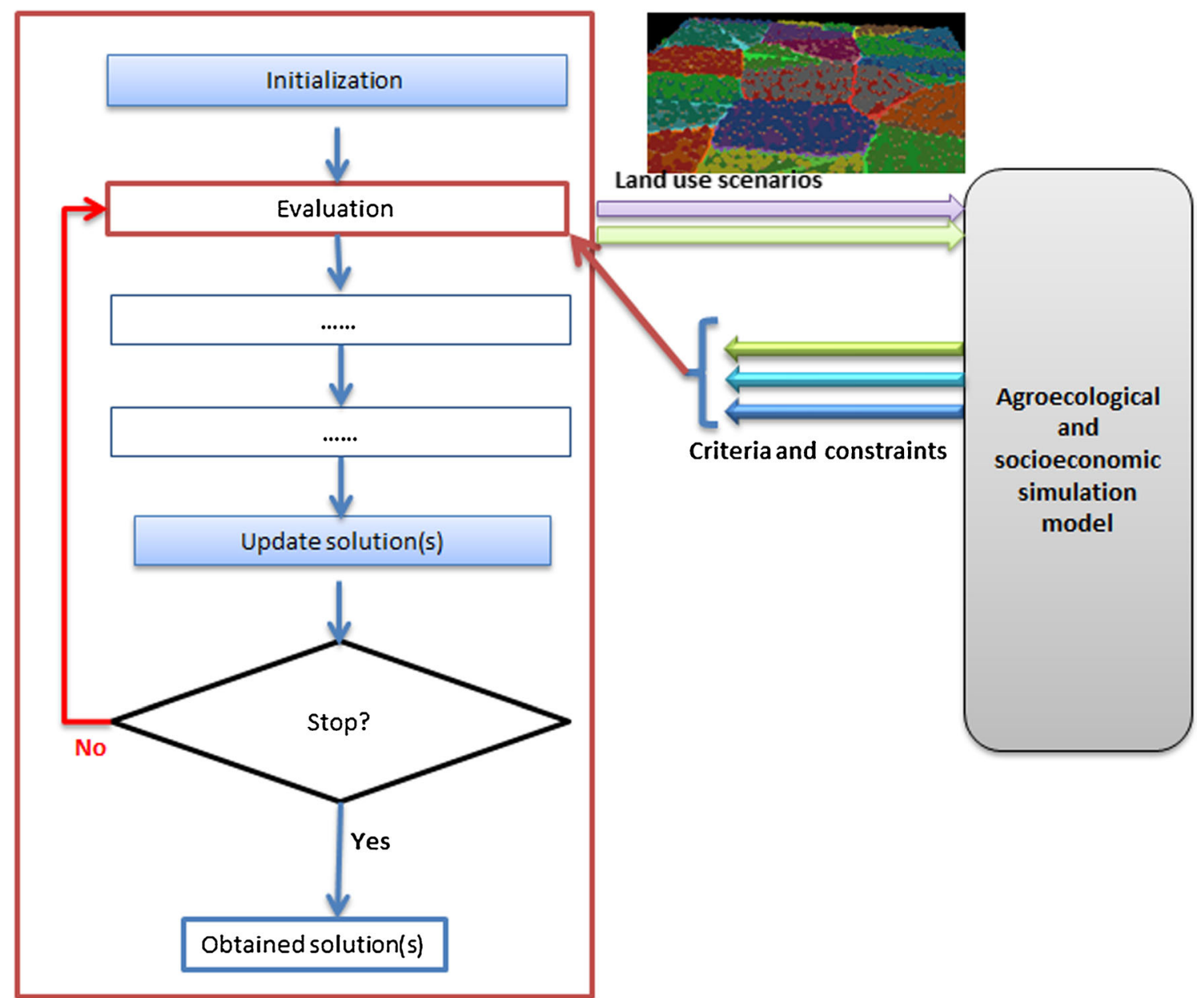

Fig. 3 Coupling metaheuristics to mechanistic models to design land use scenarios. The mechanistic models are used at the evaluation stage, which is common between all metaheuristics in order to estimate the quality of each scenario according to the considered criteria and the constraint violation 
obtained using a rule-based model and a multi-agent system. The simulated annealing resulted in better production goals but the multi-agent model was better for constraint satisfaction, viability, and computation time. Authors recommended using multi-agent models in cases where there are constraints on computation time and using simulated annealing when the decision-maker is looking for more equivalent solutions to be properly repaired, i.e., adjusted for constraint satisfaction.

The second study (Santé-Riveira et al. 2008) used simulated annealing to allocate 13 crops or covers, classified in five groups, to a set of possible land units (described by 182,168 cells with a size of $100 \mathrm{~m} \times 100 \mathrm{~m}$ ). The objective function took into account the suitability of each land unit for each use, the compactness of the total area assigned to each use, and the compactness of the total area assigned to each group of similar uses. These three criteria were aggregated into one objective function and sets of weights reflecting the importance of each criterion were applied. Authors compared the results obtained using these sets of weights to each other to analyze their impact on computation time and on criteria values. Then, they compared the results of simulated annealing with those obtained when the average suitability alone was maximized using hierarchical optimization, multi-objective land allocation, and ideal point analysis (Santé-Riveira et al. 2008). The simulated annealing outperformed the other three algorithms by identifying allocations having better suitability, but these solutions are less compact (more fragmented). Authors pointed out the weakness of simulated annealing regarding its computation time, which was considerably more than other algorithms. To deal with this drawback, authors suggested a good initialization through "good a priori land use areas".

Lastly, Chetty and Adewumi (2013) considered simulated annealing and taboo search as references to investigate the effectiveness of three local search metaheuristics for annual crop planning within a new irrigation scheme. The problem had 10 competing crops over 3764 ha (Chetty and Adewumi 2013). The objective function in this study was to maximize the gross benefits of famers subject to many constraints related to crops' allocation. The taboo search was the overall best among the five considered methods.

\subsubsection{Studies using evolutionary algorithms}

The evolutionary algorithms are, from our point of view, the most used metaheuristic to deal with the economic crop planning at a strategic level. The work conducted by Keith B. Matthews at Macaulay Land Use Research Institute, now a part of the James Hutton Institute, is among the most comprehensive in this area. Their research (Matthews et al. 1999) dealt with rural land use planning at the management unit level of an area defined by the European Union as less agriculturally favored. The study area of most of the research was a farm of 300 ha (95 fields) at the Hartwood Research Station in
Lanarkshire, Scotland. The land uses in this area are mainly spring barley, upland sheep and suckler cattle, both on sown pastures, five broad-leaved tree species and two conifer species. Objective functions varied, but they were mainly related to the maximization of the Net Present Value (NPV) of the land management (Matthews et al. 1999) and the maximization of diversity and evenness of the pattern of land use (Matthews 2001).

The used approaches were based on single-objective evolutionary algorithms and multi-objective evolutionary algorithms, with a special emphasis on the solution encoding and controlled operators considered as suitable for the land use management. Land block, Percentage, and Priority versions of multi-objective evolutionary algorithms were proposed by the authors to deal with the land use optimization problem. In Land block representation, each area of uniform land use is represented by a gene in the genotype. However, the scalability of the Land block representation and the performance of evolutionary algorithms in such a case are questionable. Also, this representation does not tolerate decisions such as splitting fields into parts or merging two fields since the genotype length is fixed. In the Percentage and Priority representation, each gene has three components: land use, priority, and target percentage.

The Percentage and Priority multi-objective evolutionary algorithm outperformed the land block multi-objective evolutionary algorithm. Contrarily, the land block evolutionary algorithm showed better performance than the Percentage and Priority evolutionary algorithm when one single criterion was considered. The authors also compared evolutionary algorithm results with 10 individuals and three collective allocations assigned by decision-makers from multiple backgrounds (biologist, agronomist, bank adviser...) with the current land use pattern (Matthews et al. 2002, 2006). Results of such a comparison revealed that the experts' allocation has sometimes poorer performance compared to the Percentage and Priority algorithm. To deal with this issue, mainly due to some implicit constraints, Proximity-Percentage and Priority algorithm was proposed. This version of Percentage and Priority takes into account the proximity between land blocks and uses a greedy algorithm.

Similarly, an evolutionary algorithm was used in (Chikumbo et al. 2012) for a more complex strategic landuse problem, i.e., the management of a farming system involving 14 criteria and covering an area of 1500 ha composed of 315 paddocks having each one between 1 and 111 management option(s). The studied farm is located east of the Rotorua city, New Zealand, and the studied farming system was composed of dairy cattle, beef cattle, sheep, planted Monterey pine forests, protected natural forests, roads, and buildings. The farm's management targeted the reduction of the environmental footprint and economic viability of farming business by identifying management strategies and their corresponding 
spatial arrangements of land uses that satisfy objectives and fulfill spatial constraints over a 50 -year planning period. The study aimed thus to optimize 14 objectives: maximizing saw$\log$ production, pulpwood production, milk solids, beef, sheep meat, wool, carbon sequestration, water production, income and earnings before interest and tax; and minimizing costs, such as nitrate leaching, phosphorus loss, and sedimentation. Many spatial constraints have been taken into account, e.g., no changes to natural forests, roads, and buildings. Taking into account the high number of criteria, the authors proposed a modified version of the Reference-point-based Nondominated Sorting Genetic Algorithm, R-NSGA-II, to deal with this many-objective optimization problem, i.e., with more than three objectives. For constraint handling, the proposed algorithm used an improved version of fitness sharing Pareto-ranking, which consists of subdividing the population into several subpopulations based on the similarity among individuals and emulating gene silencing which is an epigenetic regulation of gene expression (Chikumbo et al. 2012). The authors analyzed their results in the form of time-series and grouped criteria into three categories (productivity, profitability, environmental impact) to visually interpret these results (Chikumbo et al. 2012).

Similarly, Datta et al. (2007) dealt with the allocation of five land uses to a landscape area divided into $100 \times 100$ units in southern Portugal. The aim of this study was to predict the effects of long-term global changes on the strategic level (50 to 100 years). The authors used the well-known NSGA-II algorithm (Deb et al. 2002) in the framework of their tool called NSGA-II-LUM. The evaluation criteria used in this study were to maximize economic return, to maximize carbon sequestration, and to minimize the soil erosion (Datta et al. 2007).

Evolutionary algorithms were also used to take into account the dynamics in crop planning at the strategic level in (Nanlin et al. 2008). The authors dealt with dynamics in an inter-temporal land use optimization problem, i.e., optimization over a period of time and not only at one point. The aim was to maximize the farmer's incomes over a period of time in heather moorland areas in the UK (Cordovan, Scotland), where sheep and grouse farming compete and are managed differently. The study took into account grouse dynamics (biological), grouse prices change (economical), and subsidy (economical, e.g., European Union common agriculture policy) dynamics. Three types of tenant farmers were considered: a tenant who only considers the current time in his/her decision, a short-term tenant (5 years), and a long-term tenant (10 years). The problem was formulated as: how to allocate the land use to grouse shooting or sheep grazing under the dynamics and tenant determinants? Results of land use optimization by the evolutionary algorithm were compared to allocations made by agricultural experts. The authors found these two allocations to be similar and concluded on the relevance of evolutionary algorithms for dynamic land use optimization (Nanlin et al. 2008).

\subsubsection{Studies using other metaheuristics}

Other metaheuristics were used for economic crop planning at a tactical level or for agricultural policy planning at a national level. As an example of the first category, we can cite the study of Groot et al. (2012), who used a differential evolution algorithm to generate a large number of Pareto-optimal farm configurations. The proposed approach was illustrated using a 96 ha mixed organic farm located in Oastkapelle, the Netherlands. This farm comprises various crop rotations, permanent grasslands, and dairy cattle. Crop products could be for home consumption, export (cash crops), or to feed milk cows. The algorithm had to determine optimal farm reconfigurations satisfying four objectives and fulfilling a set of hard constraints. Farm configuration was here intended as a combination of tactical choices of the areas of cultivated crops, destination of crop products, and management strategies of animals (dairy cows). The four objectives were: to maximize the operating profit (incomes) and organic matter balance (soil structure) and to minimize the labor requirement and soil nitrogen losses (leaching and denitrification). The constraints concerned the farm total area, the crop areas within each rotation, the frequencies of cultivation of each crop, the balance between dry balance supply, animal feed intake, and acceptable nutrient losses and balance. To deal with such constraints in the initial population, the authors duplicated the current configuration into $20 \%$ of their initial population as it was hard to have feasible solutions randomly generated. Results showed that relatively small modifications to the current configuration led to considerable improvements in the farm's performances (Groot et al. 2012).

An example of the second category is the Agricultural Policy Optimizer proposed by Ververidis (2008). The author combined mathematical programming (MP) and evolutionary algorithms to tackle the bi-level optimization problems resulting from the interactions between farmers and policy makers. The Agricultural Policy Optimizer uses mathematical programming to capture the production objectives of the farmer and uses the NSGA-II algorithm to optimize the policy maker's objectives. The author illustrated the proposed approach on a Scottish agricultural case study where 30 crops and grass activities had to be allocated. Three socioeconomic (maximization of land productivity maximization of labor productivity minimization of net policy cost) and two biophysical (minimization of mean predicted soil loss and minimization of mean mineral $\mathrm{N}$ use per unit area) criteria were considered. Four political instrument scenarios were also studied. Three of these were economic instruments (single payment scheme, land use subsidies, and nitrogen taxation scheme) and the fourth one was based on a set of regulatory 
constraints (Ververidis 2008). The NSGA-II algorithm, within the Agricultural Policy Optimizer, creates a population of candidate solutions consisting of a set of policy instruments of variable complexity. Each candidate is then evaluated as a farmer's optimization problem using the mathematical programming module, and the values of the five criteria are used to assess its fitness. The best solutions, based on fitness computation, are selected to create the next generation of policy formulations. The process is repeated until the verification of a stopping criterion (McRoberts et al. 2009a, b).

Finally, in Mousa and El_Desoky (2013), the use of a fuzzy multi-objective multi-pheromone ant colony optimization approach was proposed to deal with the optimal human resource assignment in the context of reclamation of derelict land in Toshka, Egypt. The objective was to achieve four types of tasks which affect the agriculture reclamation, namely: land settlement, land planning, digging of canals, and plant cultivation. The assignment had to maximize the benefit of reclamation while minimizing the cost of agriculture reclamation.

\subsection{Water resources management}

The water resources management and the agricultural land use are strongly linked as the land use optimization could help to optimally allocate the water resources and to reduce the pollution of water resources by chemical products from farms. The studies dealing with land use optimization for water resource management purposes often took into account, in addition to farmer's income, aspects such as nutrient loss, fertilizers leaching, and sediment and pollutant agrochemical concentration levels. In the following, we respectively present some examples of studies dealing with land use allocation, studies dealing with resources such as water and fertilization allocation, and studies combining both goals for water management purposes.

\subsubsection{Land use allocation for water management purposes}

The work of Altinakar and Qi (2008) and Qi and Altinakar (2011) dealt with land use allocation for water management purposes using metaheuristics. Altinakar and Qi (2008) proposed a taboo search method for multi-objective optimization of agricultural land use in the framework of integrated watershed management. The authors applied their approach to a case study involving the management of the USDA Goodwin Creek experimental watershed located in northern Mississippi. They considered two main criteria: environmental and economic. The environmental criterion takes into account the sediment and pollutant agrochemical concentration levels in the stream. The economical criterion reflects the benefit from agricultural products and the operational cost of the land. The authors combined these two criteria using fuzzy computation in order to take account of parameter uncertainties and uncertainties in numerical model results (Altinakar and Qi 2008). In a second study, Qi and Altinakar (2011) extended their case study, using taboo search, to three objectives: minimize sediment yield at key locations, minimize amplitude of pollutant concentration peaks and the pollution time, and maximize the production returns while minimizing the implementation costs and the total expense. They also took into account constraints related to the land owner's preferences, e.g., undesired, desired and not applicable land use changes, and to policy constraints related to the total area allocated to each land use (Qi and Altinakar 2011).

\subsubsection{Best agricultural management practice allocation for water management purposes}

Many authors have used metaheuristics to allocate agricultural resources for water management purposes. Examples addressed in this category are related to the optimal placement, i.e., allocation of best agricultural management practices, of the best conservation practices, and of other agricultural resources. The criteria considered in these studies are usually related to some economic aspects, such as farmer's income and implementation costs, and to the reduction of nonpoint pollution sources.

The first example of this category for dealing with the optimal allocation of water, i.e., irrigation, and nitrogen, i.e., fertilization, resources to winter wheat and maize grain crops was considered by Lehmann et al. (2013). The authors coupled the CropSyst model with an evolutionary algorithm and aimed to maximize the farmer's profit margins taking into account uncertainties through an utility function (Lehmann et al. 2013). The study was conducted under two contrasting climate change scenarios on two different sites in Switzerland.

The works of Rabotyagov et al. (2012), Panagopoulos et al. (2013) and (Liu et al. 2013b) are examples of studies aiming to optimize economic and nonpoint pollution sources simultaneously. In the first example, the authors proposed an approach for selecting watershed configurations, achieving complete trade-off frontiers between costs of agricultural conservation practices, i.e., lowest cost, and user-specified water quality improvement objectives, i.e., minimize nonpointsource pollution in the watershed. For this purpose, they coupled the SWAT water quality model with the Strength Pareto Evolutionary Algorithm 2 (Zitzler et al. 2001). The final aim was the production of maps of optimized placement of user-specified set of conservation practices allowing the best compromise between the abovementioned objectives (Rabotyagov et al. 2012). In the second study, Panagopoulos et al. (2013) used a multi-objective evolutionary algorithm to determine optimal selections and locations of agricultural best management practices, achieving acceptable catchment management solutions with respect to environmental and economic objectives. The environmental objectives concern the 
nonpoint source pollution estimated through the SWAT model. The sum of the annual total phosphorus and the nitratenitrogen losses to surface waters were considered as environmental criteria in this study. For the economic part, the implementation cost of several types of best management practices, such as nutrient application, crop, soil, and livestock management, were considered. The authors illustrated their approach on a case study from Arachtos catchment in Greece with 51 potential agricultural best management practices and 251 hydrologic response units (Panagopoulos et al. 2013). In the third example, the authors coupled the $\varepsilon$-NSGA-II multiobjective genetic algorithm (Kollat and Reed 2006) with the SWAT model to design agricultural best management practices, reducing nonpoint-source pollution. To reduce the computation time, the authors proposed a parallelization technique. The approach was tested in the Fairchild Creek watershed in southern Ontario of Canada. Two criteria were considered, namely to minimize the agricultural best management practice implementation costs and to maximize total phosphorous load reduction (Liu et al. 2013b).

Finally, Yu et al. (2011) used an ant colony algorithm for classification rule discovery in the framework of land-use suitability assessment. The approach was illustrated by a case study from Macintyre Brook Catchment of southern Queensland in Australia. The land-use suitability was evaluated for irrigated agriculture taking into account percent slop, soil texture, depth to water table, electrical conductivity of groundwater, and hydraulic conductivity of soil (Yu et al. 2011).

\subsubsection{Land and resources allocation for water management purposes}

A third category of studies with water management purposes aims to simultaneously optimize land use and agricultural resource allocation. Seppelt and Voinov (2002) combined local optimization, Monte Carlo simulation, and an evolutionary algorithm to determine optimal land use patterns and fertilizer application maps, maximizing crop yields and minimizing the nutrients outflow in order to investigate the impact of land use on the water and matter dynamics. The above criteria were aggregated into one economic criterion, integrating the profit from crop yields, the cost of fertilizers, and the amount of nitrogen leaching transformed into a financial penalty. The approach was applied to the Hunting Creek Watershed, MD; USA; which had as main land uses forest and agricultural habitats. The used model took into account hydrological processes as well as nutrient cycling and captured the response of algal and macrophytes communities to nutrient concentrations, water, and environmental inputs. The landscape was represented as a grid of square cells with seven possible land uses: soybeans, winter wheat, corn, fallow, forest, cities, and rural areas. The authors stated that the proposed approach allowed them to identify areas with high retention capacities (Seppelt and Voinov 2002). In their second paper (Seppelt and Voinov 2003), the authors extended the previous work by considering three ecological criteria and farmer's incomes. The ecological criteria were the net primary production reflecting the overall ecosystem services provided by land use type, e.g., retention capacities of nutrients and the uptake of greenhouse $\mathrm{CO}_{2}$, nutrients outflow out of a grid cell measuring the overconsumption of retention capacity of the ecosystem, and the amount of surface water baseflow in the streams reflecting how the land use affects the hydrologic conditions, i.e., vulnerability to drought and floods. Economic and ecological criteria were aggregated into one performance objective where three weights are assigned to ecological indicators. The authors reduced the optimization task to the local method and explored the land use by considering scenarios defined by the weights. They also compared the results from local optimization to existing landscapes using a pattern matching algorithm (Seppelt and Voinov 2003).

Another example of this category was from Georgiou and Papamichail (2008), who used a simulated annealing algorithm to determine reservoir release policies and land use strategies, optimizing farmer's incomes and taking into account soil water balance. They aimed to allocate cultivated areas and water quantity to each crop. The case study used to illustrate the proposed approach was originated from a planned reservoir on the Havrias River in Northern Greece (Georgiou and Papamichail 2008).

Finally, Fotakis and Sidiropoulos (2012) proposed a multiobjective self-organizing algorithm, i.e., an evolutionary algorithm using cellular automaton, to deal with combined land use and resources allocations. The proposed algorithm used suitable transition rules, through cellular automaton, to deal with local and global spatial constraints. The authors applied their approach to a small hypothetical case study of water and land use allocations and compared their results to those identified by NSGA-II and concluded the superiority of their algorithm (Fotakis and Sidiropoulos 2012). More recently, the same authors used an evolutionary algorithm to deal with a combined land use and water allocation problem. This new study considered a hypothetical case study but also a realworld cultivated area situated in South Cyprus (Fotakis and Sidiropoulos 2014). The authors aimed to optimally distribute five irrigated crops as well as their irrigation sources. The economic return after deduction of water pumping and transportation costs was used to evaluate allocation strategies alongside with ecological constraints. In the same way, Ortega Álvarez et al. (2004) proposed an evolutionary algorithm to identify optimal cropping patterns and irrigation strategies. The case study related to 15 crops was a semi-arid irrigated area in Castilla-La Mancha region, Spain (Ortega Álvarez et al. 2004). The authors aimed to maximize the farmer's gross 
margin and used a risk associated to annual climatic change to select the best solution.

\subsection{Nature conservation in landscapes}

In this section, we review the use of metaheuristics for landscape ecology. Here, the objectives are to optimize land use in order to guarantee a good distribution of species in relation to agricultural landscape structure, or to optimize the combination of agricultural land use and landscape element configuration, in order to improve habitat quality and nature conservation and restoration. Two main groups of studies dealing with land use optimization for nature conservation purposes can be distinguished.

\subsubsection{Resources allocation for nature conservation purposes}

Some studies in this category are dealing with land use or resource allocation or reallocation. Aerts and Heuvelink (2002) used a simulated annealing algorithm for the restoration of a former mining area for new land uses, e.g., forest, shrub, and water. The restoration has to be done at lowest costs through minimizing the development costs while creating high natural values, i.e., forest and water zones, by maximizing the compactness of land use. Constraints regarding the proportion of each land use have been considered in order to restore the mine as close as possible to the pre-mining situation. The proposed approach was applied to a case study of an open cast lignite mine of As Pontes in Galicia, in the North Western part of Spain (Aerts and Heuvelink 2002).

Loonen et al. (2006) used an evolutionary algorithm in the context of the reduction of nitrogen emission sources. Their objective was to improve the quality of the Dutch nature reserve, including water resources, by minimizing the effects of atmospheric nitrogen deposition in nature areas. The case study was from the region of Noord-Brabant, where intensive agricultural and farming systems cohabite with natural reserves and forests. The authors dealt with this problem as a reallocation of nitrogen emission sources, in terms of intensive or extensive agriculture, by "designing some areas where the nitrogen emission level is allowed to increase and other areas where the emission level will have to decrease" (Loonen et al. 2006). The objective function was to minimize the sum of exceedances of critical loads in natural areas. The optimization was subject to many constraints such as keeping the total, i.e., global, emission in the area at the same level to keep the local emission level in each cell at an acceptable level, i.e., bounds; no deposition in other zones was allowed, and no increase of the deposition level was allowed in the natural areas. This approach allowed reducing considerably the exceedances of critical loads in natural areas. This reduction ranged from 71 to $27 \%$ in different cases.

\subsubsection{Reconfiguration of existing landscape for nature conservation purposes}

Others studies dealt with the reconfiguration of the shape of the existing landscape through the introduction of new linear elements and/or other new land uses. The first group of studies used different metaheuristics based on a generalized goal programming approach. In this approach, the decision-maker states not his detailed preferences, but only a point of value of criteria in the outcome space, called a reference point, and the computer optimizes "such ad hoc formulated approximation of the preferences of the decision-maker that is consistent with the stated reference point" (Aerts et al. 2003b). The case study treated by this group was the Jisperveld area situated in Northwest of the Netherlands, which was described as the largest connected brackish fen-meadow area in Western Europe. This area is of high nature value due to the presence of various wetland vegetation types, such as sundew, peat heather and various types of orchids, and due to the existence of many rare bird species, such as the black tailed godwit, common zeds hank and lark.

Aerts et al. (2003b) used simulated annealing and reference point approach to solve high-dimensional optimization problems for multi-site land use allocation. The objective of this study was to optimally allocate nine land uses, including two new, i.e., future, land use types: "extensive agriculture" and "water" in the context of governmental planning policy, for land use changing from a predominated agriculture area to a combined agriculture and nature area. Two criteria were considered for optimization and aimed to minimize the implementation costs and maximize the compactness of the allocated land use (Aerts et al. 2003b). Stewart et al. (2004) dealt with a similar problem and used the same geographical zone to illustrate their approach. The approach was the same as previously but used an evolutionary algorithm for the optimization task, which aimed to maximize both natural and recreational values of the area and to minimize the costs of land use changes (Stewart et al. 2004). Janssen et al. (2008) considered six objectives, including the same three objectives as in Stewart et al. (2004) and three spatial objectives aiming to minimize the fragmentation and to maximize the largest cluster and the compactness. The approach was tested through an interactive session with the decision-makers who were asked to give their feedback at the beginning of the land use allocation (Janssen et al. 2008).

Groot et al. (2007, 2010) used differential evolution algorithms. The case study was to redesign the linear landscape elements in an agroecological zone in The Netherlands. This case study was related to the Northern Frisian Woodlands, where environmental cooperatives and other stakeholders were investigating adjustments and reconfigurations of a grassland-dominated landscape with hedgerows bordering the fields. In their first paper, Groot et al. (2007) used the 
Landscape IMAGES framework and a differential evolution algorithm to help decision-makers from various backgrounds to investigate the trade-offs between nature conservation, agricultural profit, and landscape quality and biodiversity. The adjustments of land-use intensity and hedgerows presence aimed to optimize four objectives reflecting the opinions of various stakeholders. These objectives were to maximize the farmer's gross margin by guarantying an acceptable agronomic yield, to maximize the diversification of the botanical composition of fields and hedgerows, to maximize variation in plant communities in the fields and half-openness of the landscape, and to minimize nutrient losses to the environment. Two constraints regarding the limits on nutrient inputs and the proportion of herbage grazed were also taken into account (Groot et al. 2007). Groot et al. (2010) extended the previous study by using a similar approach to redesign spatial configurations of hedgerows, optimizing a set of seven objectives (Groot et al. 2010). The considered objectives were related to the ecological quality, landscape character, and implementations costs. To deal with seven objectives, the authors used the Pareto efficiency defined by Das (1999) and the crowding distance proposed by Deb et al. (2002).

Interested readers are invited to consult comprehensive review on forest management conducted by (Baskent and Keles 2005). That review gave additional examples using metaheuristics and other optimization algorithms for forest management. Another rich review of the biodiversity conservation planning tools was (Sarkar et al. 2006) and is highly recommended for further reading.

\subsection{Multifunctional agricultural landscapes}

Many land use optimization studies are of general purposes and therefore include agricultural and others green land uses to be assigned. We present hereafter some examples of such studies classified following the used metaheuristic.

\subsubsection{Studies using genetic algorithms}

Evolutionary algorithms were used by Moulton et al. (2009) to investigate the land use decision-making in the context of potential habitat loss and fragmentation represented by reduction in the area and connectedness of natural land. The proposed approach combined the use of NSGA-II (Deb et al. 2002) for the optimization task and the hierarchical cluster analysis for the decision-making step to identify the most suitable configuration. The authors illustrated their approach on a small example of four land uses (urban, agriculture, natural, abandoned) and eight potential candidate sites (fields) in an urban fringe area in southern Ontario, Canada. Eight landscape-ecology metrics were considered as criteria to be maximized (Moulton et al. 2009). The NSGA-II algorithm was also used by Cao et al. (2011) for multi-objective optimization of land use. The authors applied it to the example of Tongzhou New Town, China. The objective was to allocate five land uses, optimizing three objectives and fulfilling a set of constraints reflecting the user's and land planner's restrictions. The objectives considered were to minimize conversion costs, maximize accessibility, and maximize compatibilities between land uses (Cao et al. 2011).

Cao et al. (2012) extended their previous work to investigate the problem of how to plan and manage a rapid developing area in the future. The proposed approach used a boundary-based evolutionary algorithm, based on a reference point method, and the case study was the same as above. Many criteria, such as economic, environmental and ecological benefits, social equity including gross domestic product, conversion cost, geological suitability, ecological suitability, accessibility, Not In My Back Yard influence, compactness, and compatibility, were taken into account (Cao et al. 2012). Similarly, Porta et al. (2013) used parallel genetic algorithms to design a spatial decision support system for the development of municipal land use plans in Galicia, northwest Spain. The approach took into account legal rules and constraints on some existing land uses in some areas, i.e., no change allowed. Four non-fixed categories, namely nature, agriculture, forestry, urban, had to be allocated, optimizing two criteria and fulfilling the constraints. Criteria were related to land suitability and the shape regularity of the resulting land use patches (Porta et al. 2013).

Finally, a multi-objective evolutionary algorithm was developed by Morio et al. (2013) to deal with the problem of reusing underused or abandoned contaminated land, so-called brownfields, for reducing the consumption of land and natural resources. The authors aimed to identify land use configurations by optimizing a set of criteria. The approach was illustrated using a case study of a former military site near Potsdam, Germany. The criteria taken into account in this study were related to some sustainability indicators and economic aspects, including remediation costs and land values (Morio et al. 2013).

\subsubsection{Studies using particle swarm optimization}

Many studies dealt with land use for multifunctional agriculture using particle swarm optimization and multi-objective particle swarm optimization. A particle swarm algorithm was used by Ma et al. (2011) to investigate a township land use planning with 10 potential land uses, including agriculture, residential, mines, dry fields, forests, and pools. The criteria taken into account in this study were to minimize the expenses for land use changes, to maximize the suitability for the targeted land use, and to maximize the compactness of the land uses (Ma et al. 2011). In the same way, Masoomi et al. (2012) proposed a multi-objective particle swarm optimization algorithm to find the optimal arrangement of urban land 
uses at the parcel level, satisfying four objectives and some constraints simultaneously. The objectives were to maximize compatibility, dependency, suitability, and compactness of land uses. The authors considered data of region 7, district 1 of Tehran, to illustrate their approach (Masoomi et al. 2012). Huang (2010) used a particle swarm optimization algorithm to deal with the land use structure optimization problem. He aimed to maximize the gross domestic product and the total ecological value of land ecosystem. This optimization was subject to many constraints, e.g., social, land use rates, suitability. The author illustrated the proposed approach on the land use structure optimization for HeChuan District of ChongQing City (Huang 2010).

Hybrid particle swarm algorithms have also been used for land use optimization. Liu et al. (2013a, 2013b, 2013c) dealt with land use allocation in the context of countries under severe environmental and demographic pressures, taking into account demands based on scenarios, influenced by economy, technology, population, policy, and their interactions at macro-level scales. The proposed approach integrated a system dynamics model and a hybrid particle swarm optimization algorithm using different variation operators. The authors applied the proposed approach to a case study in Panyu, Guangdong, China, aiming to maximize the total suitability of land use map, minimize the distance of new development to already developed sites, maximize the compatibilities of each cell and its neighborhood, and maximize the compactness of a land use. Five land uses: industry, commerce, residence, undeveloped such as agriculture and orchards, and restricted land such as water, ecological preservation zone, were considered (Liu et al. 2013a).

\subsubsection{Studies using ant colony algorithms}

Ant colony algorithms have also been used for land use optimization of general purposes. Liu et al. (2013c) proposed to use the global search capability and information feedback mechanism of ant colony algorithm and graph modeling to deal with a land use spatial allocation problem. The aim was to improve the land use efficiency by allocating different land uses, e.g., cropland, gardens, forestland, towns, under the limits of regional land use structure according to specific planning objectives at different spatial and temporal scales. The case study focused on Gaoqiao Town of Fuyang City in Zhejiang Province, China. The authors aimed to maximize the land use suitability, to maximize spatial compactness and unchanged rate under a variety of constraints, e.g., optimal land use structure and land use policies. These criteria were aggregated using a weighted sum method (Liu et al. 2013c). Yang et al. (2012) proposed an approach combining an ant colony algorithm, Markov chains, and cellular automata for the simulation and optimization of spatiotemporal land use changes. The proposed approach aimed to determine local transition rules of land use changes by conducting a reasonable local rule discovery process. The authors illustrated their approach on a rapidly growing area, i.e., Changping, a district of Beijing, having five potential land uses. The criterion considered in this work was the rule prediction quality (Yang et al. 2012).

\subsubsection{Studies using other metaheuristics}

Although evolutionary algorithms, particle swarm optimization, and ant colony optimization were the most used metaheuristics, other metaheuristics were also used for land use optimization. Duh and Brown (2007) developed a knowledge-based Pareto simulated annealing algorithm for multi-objective land use optimization. The authors compared their algorithm to a classical Pareto simulated annealing algorithm. The performances of these algorithms were compared using a benchmark of four hypothetical land use optimization problems. The criteria considered for optimization were related to some spatial patterns and non-pattern objectives. The knowledge-based Pareto algorithm showed better performances compared to the classical algorithm (Duh and Brown 2007), Eldrandaly (2010) proposed the use of Gene Expression Programming for solving the Multisite Land Use Allocation Problem. He considered a fictive case study to illustrate his proposed approach. Two criteria were taken into account, namely the minimization of the development costs and the maximization of the compactness of the land uses. He considered also the coverage of three land use types as predefined, i.e., as constraints (Eldrandaly 2010).

In summary, the use of metaheuristics for land use optimization is now well established as a large number of research publications dealing with this problem are available in the literature. Contrary to our initial expectations, the choice of a given metaheuristic for solving a given land use optimization problem was mostly driven by the historical use in the research teams and affinities between scientific communities, rather than by the characteristics of the problem at hand. Table 1 summarizes eight representative examples using metaheuristics for land use optimization, i.e., two examples from each category in our review. This table summarizes the reviewed work by its category, objectives, used metaheuristic, criteria and constraints, land uses and the available land area.

\section{Discussion}

In spite of the popularity of using metaheuristics for land use optimization, there are still many interesting research issues that are worth further discussing. 


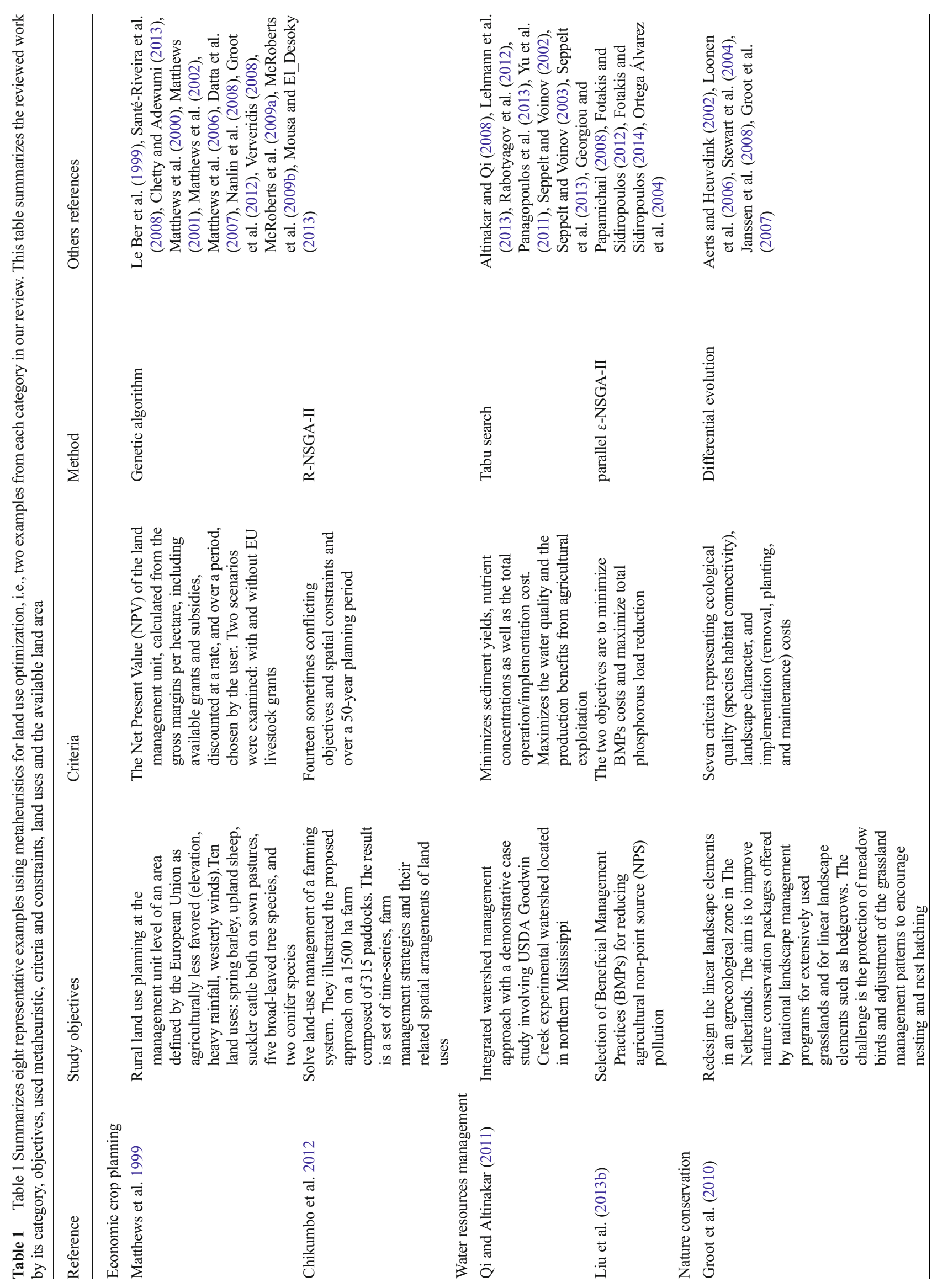


$\hat{\overline{0}} \hat{\overline{0}} \hat{\sigma} \hat{0}$

d d d d d

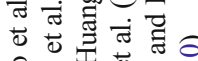

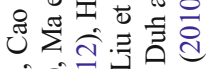

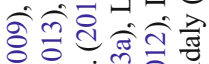

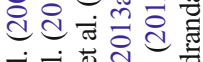

तं बं

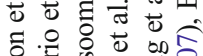

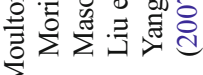

这

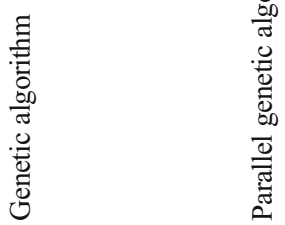

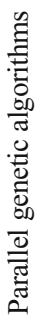

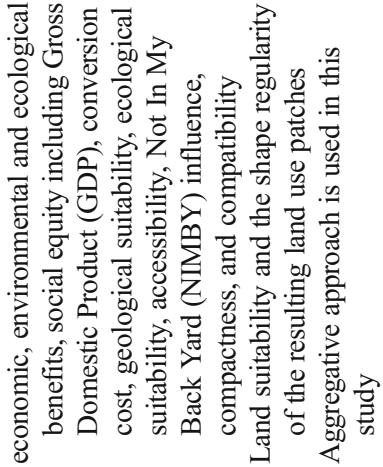

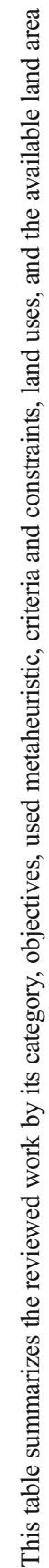
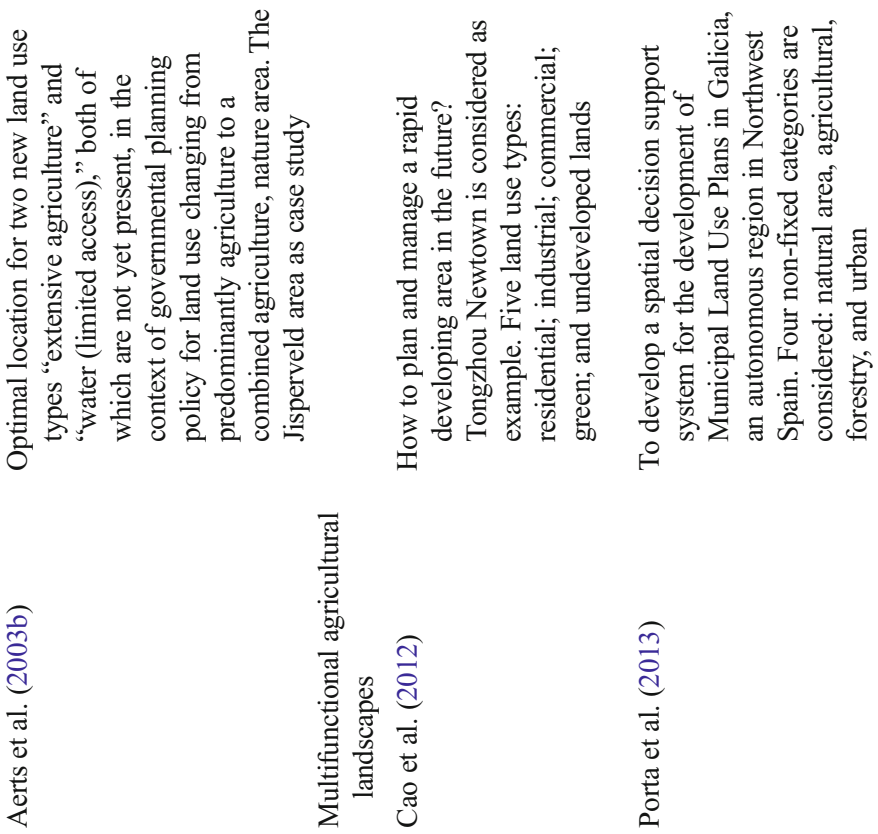

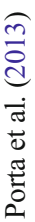

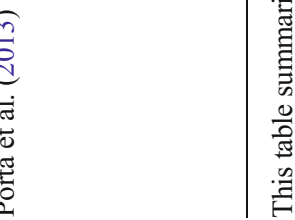




\subsection{Impact of the history of research communities}

The first point we would like to discuss is the historical link and affinity between some research communities dealing with land use optimization and some metaheuristics. One reason of this historical links, let us say specialization, could be the historic divorce between research communities developing some metaheuristics during the first two decades of their existence. Indeed, as stated by Blum et al. (2011), "during the first two decades of research on metaheuristics, different research communities working on metaheuristic techniques coexisted without much interaction, neither among themselves nor with operations research community."

As pointed out by Matthews (2001), simulated annealing and taboo search, both taking their roots in the neighborhood search method, are two popular methods in forest management. This could be partially explained, especially for simulated annealing, by the principles of these methods and their closeness to the operations research community and thus to the agronomic and forestry communities. Taboo search might be seen as an attempt to improve the performance of simulated annealing by learning from the past, through a taboo list, and thus integrating the concept of memory inspired by the similar mechanism in human beings (Boussaïd et al. 2013).

Similarly, evolutionary algorithms, particle swarm optimization, and other metaheuristics have been introduced relatively later to the land use community due to the development of such algorithms by their own communities. These methods were used to tackle the increase of complexity in land use optimization problems. Such complexity is mainly caused by the change of decision-makers' points of views and their competing criteria. Although more sophisticated metaheuristic algorithms have been developed in the metaheuristic communities, especially in the evolutionary computation community, such advanced algorithms have not propagated to the land use optimization community, partly because of time and partly because the more advanced algorithms are not as straightforward as their basic forms, which creates barriers for their wider and faster adoption. More and closer collaborations between metaheuristic researchers and land use researchers are needed in the future.

\subsection{An increasing number of objectives and constraints: scalability of metaheuristics}

The increasing number of criteria and constraints involved in land use optimization problems pose challenges to researchers and engineers. The optimization problems involving more than three criteria are often called many-objective optimization problems in the evolutionary computation community. It is well known that the Pareto dominance, the most often used relationship in the field of multi-objective optimization, is inappropriate in the context of many-objective optimization.
Indeed, it has been shown that when the number of objectives increases, the number of non-dominated solutions increases exponentially (Handing and Xin 2014). This drawback of Pareto-based multi-objective optimization algorithms has a direct impact on the ability of such algorithms to progress towards the Pareto-Optimal front. Therefore, many studies have been carried out in order to propose comparison operators that are able to overcome the drawback of the Paretodominance operator in such algorithms. The scalability of metaheuristics, especially multi-objective evolutionary algorithms, to many objectives has been treated through different approaches. The main approaches are the modification of the Pareto dominance relation, the introduction of different ranks, the use of indicator functions, the use of scalarization functions, the use of preference information, and the reduction of number of objectives (Ishibuchi et al. 2008).

The modification of the Pareto dominance relation through many relaxation forms has been proposed in the literature to improve its comparability abilities. The alpha dominance, the epsilon dominance, and the local dominance relation are examples of such modifications (Rui et al. 2013). The idea of introducing different ranks is to use other dominance relations, which might be able to differentiate solutions that Paretodominance relation cannot. The relation, favor, based on the number of criteria favoring one solution to another and the relation, epsilon-preferred extending the favor relation to take into account the difference in the objective values of the two solutions, are examples of such an approach (Rui et al. 2013).

Indicators were initially designed to evaluate the performance of metaheuristics. Later, researchers have used these indicators within the optimization algorithms. Examples are the indicator-based evolutionary algorithm, the S metric selection multi-objective evolutionary algorithm, and the hypervolume-based algorithm (Rui et al. 2013).

The scalarization approach transforms the original manyobjective optimization problem into a single-objective one using methods such as weighted sum and Tchebycheff functions. Ishibuchi et al. (2008) distinguished two types of scalarization approaches. The first approach assigns to each solution a number of ranks according to each performance criterion against a set of scalarization functions. In this approach, every solution receives many ranks, e.g., according to each objective, and then the final rank of this solution is determined by an appropriate method, e.g., min operator. The second approach uses a single scalarization function, e.g., weighted sum, to calculate the rank of each solution (Ishibuchi et al. 2008).

The incorporation of the decision-maker preferences into metaheuristics could improve the comparability between solutions otherwise incomparable using the Pareto-dominance relation. Examples of such an approach were cited by Ishibuchi et al. (2008). Two recent algorithms using this approach were described in (Rui et al. 2013) and (Sinha et al. 
2010). The idea of the dimensionality reduction approach is to identify the smallest set of conflicting objectives. The reduction could be done using machine learning techniques such as principal component analysis, maximum variance unfolding (Sinha et al. 2010), nonlinear correlation information entropy (Handing and Xin 2014), or unsupervised feature selection algorithms.

Although agricultural land use optimization usually involves many criteria, examples of the use of many-objective optimization algorithms to deal with land use allocation are rare. We can only point to Chikumbo et al. (2012) and Groot et al. (2010). The weighted sum approach remains the most used method despite its well-known drawbacks.

\subsection{Which metaheuristic for which problem?}

The choice of the suitable metaheuristic to deal with a given optimization problem is of great importance for the end users. This choice could help tackling emerging problems more efficiently and avoiding the use of poor-performing metaheuristics. However, this question is very difficult and there are some ongoing research efforts to understand how and why one metaheuristic outperforms another for tackling some optimization problems (He et al. 2014). The fitness landscape analysis, in the metaheuristics community, can be a promising idea for this purpose (He et al. 2007). According to Pitzer and Affenzeller (2012), the fitness landscape analysis is commonly used to better understand the performance and the progression "through the landscape" of a given heuristic on a problem instances (Pitzer and Affenzeller 2012). The use of such a concept allows characterizing local optima, plateaus, basins of attraction, and barriers. One can question the usefulness of fitness landscape analysis as it is consuming time and resources that could be used for solving the optimization problem at hand. However, the use of fitness landscape analysis could help understanding the metaheuristic and the problem. It could help developing better metaheuristics for land use optimization.

Although it is very difficult to advise a good metaheuristic for a given problem, some observations could be made towards the choice of metaheuristics to use. For example, taboo search and simulated annealing seem to have performed well for cases where there are many constraints, making moves within the search space satisfying such constraints and random generation of feasible solutions very difficult. Examples of such situations are reconfiguration studies aiming to introduce the smallest number of changes, e.g., hedgerows, into a landscape to improve nature conservation. Evolutionary algorithms were preferred for handling multiple conflicting objectives. In many applications, hybrid algorithms that combine an evolutionary algorithm with local search seem to be very effective and efficient, because they tend to balance exploitation and exploration better in search.

\subsection{Balancing the trade-off between exploration and exploitation: hybridization}

Some metaheuristics are known to be more explorative, while others are reputed to be more exploitative. As a consequence, sometimes, simple metaheuristics can show poor performances in dealing with some hard problems, such as agricultural land use optimization. To tackle this issue in practice, the metaheuristic research community suggested the combination of different algorithms having different abilities to improve the performances of single algorithms. This technique, commonly called hybridization, aims to take advantages of the strength of each algorithm and avoid as much as possible its drawbacks. Many kinds of hybridization are possible and already available in the literature including techniques combining one metaheuristic with another metaheuristic (Tang et al. 2014), with constraint programming, with local search method, with tree search technique, with problem relaxation, and with dynamic programming. However, developing hybridization techniques is a difficult task. Blum et al. (2011) recommended that the greatest caution should be taken before engaging in such an adventure and to not go further if the hybridization is unnecessary. The use of hybrid metaheuristics for land use optimization is still rare. Some examples of this approach can be found in (Liu et al. 2013a; Aerts et al. 2003b; Seppelt and Voinov 2002; Yang et al. 2012). Interested readers are kindly invited to consult the paper of Blum et al. (2011) for more details on hybrid metaheuristics.

\subsection{Adapting computational facilities to handle a large number of decision variables and dynamics}

One of the most important issues in dealing with agricultural land use allocation is the geographical resolution and its impact on the number of decision variables involved in the resulting optimization problem. As researchers and decisionmakers are increasingly investigating agricultural systems on a large scale and with more and more emphasis on the local level, the explosion of the number of decision variables seems unavoidable. Moreover, some of the used models may have some temporal and dynamic aspects and need the solution of differential or partial differential equations at each step. Examples of such phenomenon are population dynamics models used in the context of integrated pest management. Another example is the design of conservation strategies in a dynamic context where proposed solutions must be updated on the basis of new information and following the changing situations (Sarkar et al. 2006). The impact of such aspects on the computation time of metaheuristics could be very severe.

Parallel computing techniques constitute potential solutions to the increasingly long computation time problem. Population-based metaheuristics, such as evolutionary 
algorithms, are very appropriate for parallelization to speed up the evaluation of solutions. Examples using parallel evolutionary algorithms for land use optimization include (Porta et al. 2013; Liu et al. 2013b).

\subsection{Decision-making issues: integrating the knowledge of decision-makers}

The goal of land use optimization is to support decisionmakers and not to exclude them from the whole allocation process (Sarkar et al. 2006). Metaheuristics allow generating a set of Pareto-optimal solutions represented by spatial configurations and/or crops allocations, but do not take into account the decision-making task, i.e., choice of the most suitable configuration(s) to be implemented from all candidates. In published early work, the results of the optimization using metaheuristics were submitted to decision-makers who had the task to choose the most appropriate solutions with no more support. Basic tools such as graphical representation and some statistical analysis were then used by decision-makers in making the choice. Such tools have some limitations, especially in cases with high dimensional problems. Therefore, researchers proposed the use of many multi-criteria decision-making methods, which are more powerful approaches to decisionmaking. For instance, (Store and Kangas 2001) integrated spatial multi-criteria evaluation and expert knowledge for GIS-based habitat suitability for species. The method, using the multi-attribute utility theory, was illustrated on a case study in which habitat suitability maps were produced for an old-forest polypore. Van Huylenbroeck (1997) combined several multi-attribute utility theory methods for the analysis of the trade-offs between economic and environmental objectives in rural planning (Van Huylenbroeck 1997). In the context of agricultural land allocation, the multi-criteria decisionmaking methods were generally used independently of the optimization process.

More recently, some attempts have been made to bridge the gap between the metaheuristics and the decision-making methods used in land use optimization. The aim here is to use metaheuristics and multi-criteria decision-making interactively to help decision-makers search towards some promising regions and to be realistic about the performance of used algorithms. Depending on the used approach and on the results of each optimization round, decision-makers can thus change the weights assigned to criteria, reconsider their reference points, or adjust their goals before launching the next round. An example of this type was presented in (Janssen et al. 2008), where the results of an interactive session with land use planners were used in the framework of a heuristic. Xiao et al. (2007) reviewed the interactive evolutionary approaches in multi-objective spatial decision-making. Their goal was to help the decision-maker to select some alternatives from the whole set of solutions generated by evolutionary algorithms and displayed using an interactive visual tool allowing to analyze trade-offs between criteria (Xiao et al. 2007). Seppelt et al. (2013) recommended to combine optimization algorithms generating Pareto-frontiers with the scenario analysis in order "to provide efficient options for sustainable land use from global to subglobal scales" (Seppelt et al. 2013). Agricultural land use allocation involves many competing actors such as farmers, farmers associations, environmental agencies, land planners, and economists. It is therefore useful to consider multi-actor decision-making methods to help all these actors finding consensus among them (as shown in Fig. 4). Approaches based on reference points and goals, as discussed above, could be very useful for such purposes.

\subsection{Methodological studies for different land use optimization problems}

All the studies that we found in the field of land use optimization were applied to specific situations for concrete applications. Further, the choice of the metaheuristics that were used was not guided explicitly by the characteristics of the problem at hand. In that context, providing advice to researchers that aim to use these methods for land use optimization is difficult. This highlights the need for in-depth studies exploring the value of different metaheuristics for different types of land use optimization problems. These problems would differ in terms of geographical resolution, e.g., number of land uses to be allocated and number of units where allocation would take place, as well as in terms of optimization goals, e.g., numbers of objectives and levels of constraints. A closer collaboration between researchers using land use simulation models and the meta-heuristics research community would help reach this goal.

\section{Conclusion}

Reducing the dependency of agricultural systems on chemical products while keeping an acceptable economic income for farmers are amongst the ultimate goals of decision-makers in many countries. Researchers are increasingly using modeling and optimization techniques to identify pragmatic and clever management strategies satisfying these objectives. Due to the complexity of these problems, classical optimization methods such as mathematical programming, local search techniques, and heuristics may not be sufficient to deal with such problems.

The use of metaheuristics for agricultural land use optimization is now deeply rooted in the scientific community and a large number of research papers related to this topic have been published. Agricultural land use optimization using metaheuristics is now pursued for various purposes, including 


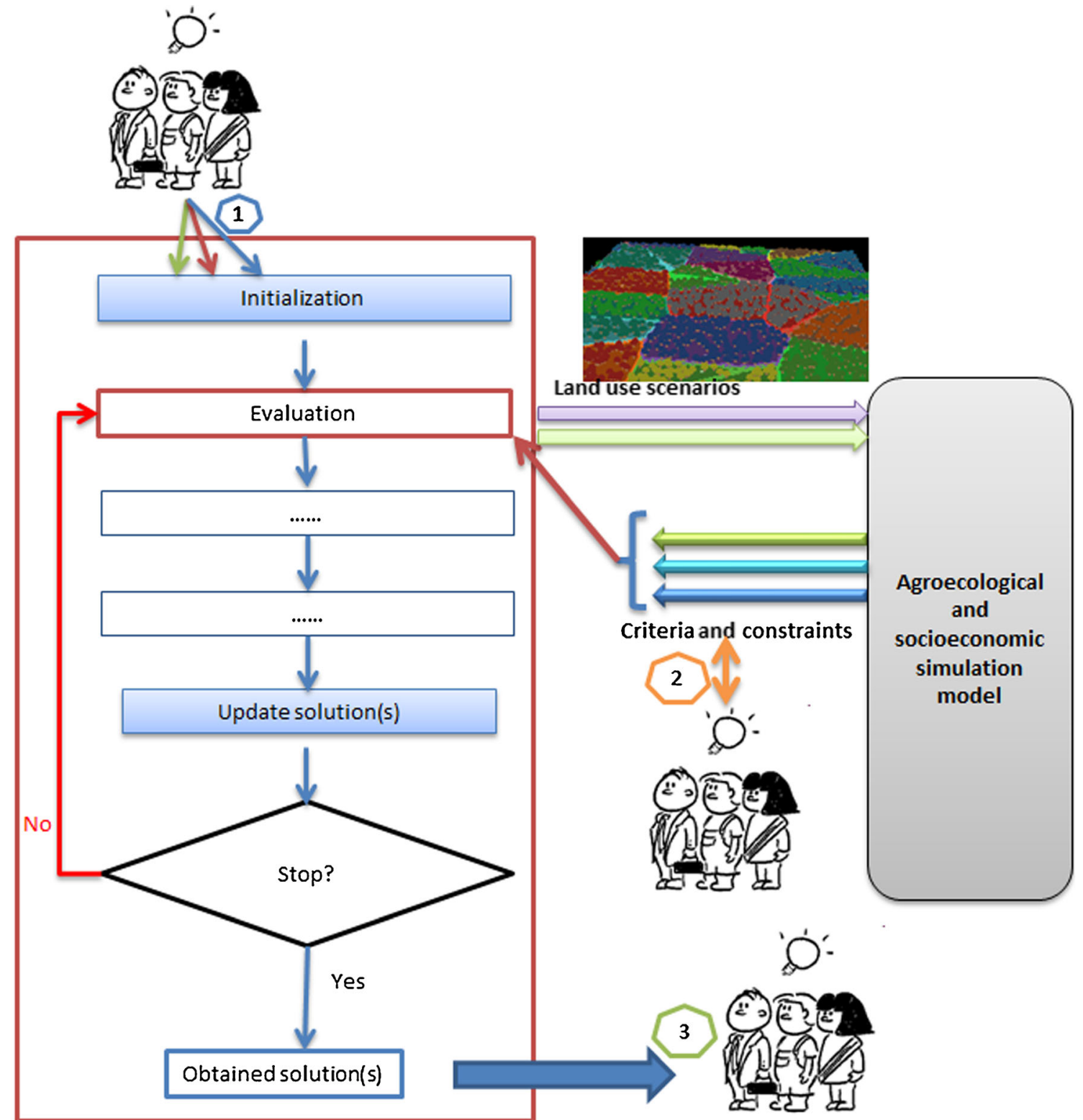

Fig. 4 Involving decision-makers and stakeholders in the process of land use design using metaheuristics is a real challenge for the future. Decision-makers can be involved in the process using a priori, interactive, and a posteriori approaches. (1) In the a priori approach, decision-makers can express their preferences, through known land use scenarios for example. (2) Interactive approaches allow decision-makers

economic crop planning, nature preservation, watershed management, and multifunctional agriculture.

As the context and objectives are evolving constantly, agricultural land use optimization has become more and more complex. New metaheuristics have to be developed to deal with such increasing complexity. For instance, decision-makers and stakeholders are nowadays interested in larger geographical zones with emphasis on local effect of management strategies. Doing so, the number of decision variables will increase and the difficulty of the problem at hand will also increase. to change their preferences during the optimization process based on their real-time analysis of the progress of simulations and their outputs. (3) In the a posteriori approach, decision-makers analyze the results of the optimization at the end of simulation. They can decide to change their preferences and go into new simulations or be satisfied with those results

Some interesting ideas have been introduced to improve the performance of metaheuristics when dealing with hard optimization problems. On one hand, the use of parallelization techniques and the use of clusters and clouds can speed up existing algorithms. On the other hand, hybridization of different metaheuristics can lead to new and more efficient algorithms. Although it is very difficult to suggest a suitable metaheuristic for a given optimization problem, some characteristics of the problem could guide this choice. For example, we could use such characteristics to choose search operators 
automatically in an evolutionary algorithm (Consoli et al. 2014). Another important issue is to help the stakeholders and decision-makers selecting one or more solution(s) from the whole set of solutions generated by a multi-objective metaheuristic algorithm. Indeed, stakeholders and decisionmakers who sometimes have competing interests are increasingly involved in the land use optimization and require interactive tools helping them to find best trade-offs reflecting their various interests and points of view.

Acknowledgments Mohamed-Mahmoud MEMMAH has received the support of the European Union, in the framework of the Marie-Curie FP7 COFUND People Programme, through the award of an agreenSkills' fellowship (under grant agreement $n^{\circ} 267196$ ).

This work has been realized in the framework of the project "PEERLESS" funded by the Agrobiosphere ANR program (ANR-12-AGRO0006). Xin Yao was supported by an EPSRC grant (No. EP/I010297/1) and a Royal Society Wolfson Research Merit Award.

\section{References}

Aerts JCJH, Eisinger E, Heuvelink GBM, Stewart TJ (2003a) Using linear integer programming for multi-site land-use allocation. Geogr Anal 35(2):148-169. doi:10.1111/j.1538-4632.2003. tb01106.x

Aerts JCJH, Heuvelink GBM (2002) Using simulated annealing for resource allocation. Int J Geogr Inf Sci 16(6):571-587. doi:10.1080/ 13658810210138751

Aerts JJH, Herwijnen M, Stewart T (2003b) Using simulated annealing and spatial goal programming for solving a multi site land use allocation problem. In: Fonseca C, Fleming P, Zitzler E, Thiele L, Deb K (eds) Evolutionary multi-criterion optimization, vol 2632. Lecture Notes in Computer Science. Springer Berlin, Heidelberg, pp 448463. doi:10.1007/3-540-36970-8 32

Akplogan M, Dury J, de Givry S, Quesnel G, Joannon A, Reynaud A, Bergez JÉ, Garcia F A weighted (2011) CSP approach for solving spatio-temporal farm planning problems. In: 11th Workshop on Preferences and Soft Constraints Perugia, Italy, pp 1-15

Alabdulkader AM, Al-Amoud AI, Awad FS (2012) Optimization of the cropping pattern in Saudi Arabia using a mathematical programming sector model. Agric Econ Czech 58:56-60

Altinakar M, Qi H (2008) Numerical-simulation based multiobjective optimization of agricultural land-use with uncertainty. In: World Environmental and Water Resources Congress, Honolulu, Hawaii, United States, May 12-16, 2008, pp 1-10. doi: 10.1061/40976(316) 481

Badarudin I, Sultan ABM, Sulaiman MN, Mamat A, Mohamed MTM (2009) Metaheuristic approaches for optimizing agricultural land areas. In: Data Mining and Optimization, 2009. DMO '09. 2nd Conference on, 27-28 Oct. 2009, pp 28-31. doi: 10.1109/DMO. 2009.5341914

Bahesti Z, Shamsuddin SM (2013) A review of population based metaheuristic algorithm. Int J Adv Soft Comput Appl 5(1):1-35

Bamière L, Havlík P, Jacquet F, Lherm M, Millet G, Bretagnolle V (2011) Farming system modelling for agri-environmental policy design: the case of a spatially non-aggregated allocation of conservation measures. Ecol Econ 70(5):891-899. doi:10.1016/j.ecolecon.2010.12. 014

Barral MP, Rey Benayas JM, Meli P, Maceira NO (2015) Quantifying the impacts of ecological restoration on biodiversity and ecosystem services in agroecosystems: a global meta-analysis. Agric Ecosyst Environ 202:223-231. doi:10.1016/j.agee.2015.01.009

Baskent EZ, Keles S (2005) Spatial forest planning: a review. Ecol Model 188(2-4):145-173. doi:10.1016/j.ecolmodel.2005.01.059

Blum C, Puchinger J, Raidl GR, Roli A (2011) Hybrid metaheuristics in combinatorial optimization: a survey. Appl Soft Comput 11(6): 4135-4151. doi:10.1016/j.asoc.2011.02.032

Boussaïd I, Lepagnot J, Siarry P (2013) A survey on optimization metaheuristics. Inf Sci 237:82-117. doi:10.1016/j.ins.2013.02.041

Brooker L (2002) The application of focal species knowledge to landscape design in agricultural lands using the ecological neighbourhood as a template. Landsc Urban Plan 60(4):185-210. doi:10.1016/S0169-2046(02)00055-5

Callesen I, Grohnheit PE, Østergård H (2010) Optimization of bioenergy yield from cultivated land in Denmark. Biomass Bioenergy 34(9): 1348-1362. doi:10.1016/j.biombioe.2010.04.020

Campbell JC, Radke J, Gless JT, Wirtshafter RM (1992) An application of linear programming and geographic information systems: cropland allocation in Antigua. Environ Plan A 24(4):535-549. doi:10. 1068/a240535

Cao K, Batty M, Huang B, Liu Y, Yu L, Chen J (2011) Spatial multiobjective land use optimization: extensions to the non-dominated sorting genetic algorithm-II. Int J Geogr Inf Sci 25(12):19491969. doi:10.1080/13658816.2011.570269

Cao K, Huang B, Wang S, Lin H (2012) Sustainable land use optimization using boundary-based fast genetic algorithm. Comput Environ Urban Syst 36(3):257-269. doi:10.1016/j.compenvurbsys.2011.08. 001

Chetty S, Adewumi AO (2013) Three new stochastic local search metaheuristics for the annual crop planning problem based on a new irrigation scheme. J Appl Math 2013:14. doi:10.1155/2013/ 158538

Chikumbo O, Goodman E, Deb K (2012) Approximating a multidimensional Pareto front for a land use management problem: a modified MOEA with an epigenetic silencing metaphor. In: Evolutionary Computation (CEC), 2012 I.E. Congress on, 10-15 June 2012, pp 1-9. doi: 10.1109/CEC.2012.6256170

Chuai X, Huang X, Lai L, Wang W, Peng J, Zhao R (2013) Land use structure optimization based on carbon storage in several regional terrestrial ecosystems across China. Environ Sci Pol 25:50-61. doi: 10.1016/j.envsci.2012.05.005

Consoli P, Minku L, Yao X (2014) Dynamic selection of evolutionary algorithm operators based on online learning and fitness landscape metrics. In: Dick G, Browne W, Whigham P et al (eds) Simulated Evolution and Learning, vol 8886. Lecture Notes in Computer Science. Springer International Publishing, pp 359-370. doi: 10. 1007/978-3-319-13563-2 31

Cordon O, Herrera F, Stützle T (2002) A review on the ant colony optimization metaheuristic: basis, models and new trends. Mathware Soft Comput 9:141-175

Cotter M, Berkhoff K, Gibreel T, Ghorbani A, Golbon R, Nuppenau E-A, Sauerborn J (2014) Designing a sustainable land use scenario based on a combination of ecological assessments and economic optimization. Ecol Indic 36:779-787. doi:10.1016/j.ecolind.2013.01.017

Dai ZY, Li YP (2013) A multistage irrigation water allocation model for agricultural land-use planning under uncertainty. Agric Water Manag 129:69-79. doi:10.1016/j.agwat.2013.07.013

Das I (1999) A preference ordering among various Pareto optimal alternatives. Struct Opt 18:30-35

Datta D, Deb K, Fonseca CM, Lobo FG, Condado PA, Seixas J (2007) Multi-objective evolutionary algorithm for land-use management problem. Int J Comput Intell Res 3(4):371-384

de Figueiredo M, Figueiredo M, Detomini E (2012) Optimising land use and water allocation in intercropping systems. Revista de Politica Agricola 21(1):92-102 
Deb K, Pratap A, Agarwal S, Meyarivan T (2002) A fast and elitist multiobjective genetic algorithm: NSGA-II. IEEE Trans Evol Comput 6(2):182-197. doi:10.1109/4235.996017

Domptail S, Nuppenau E-A (2010) The role of uncertainty and expectations in modeling (range)land use strategies: an application of dynamic optimization modeling with recursion. Ecol Econ 69(12): 2475-2485. doi:10.1016/j.ecolecon.2010.07.024

Dorigo M, Colorni A, Maniezzo V (1991) Positive feedback as a search strategy, vol Technical Report

Duh J-D, Brown DG (2007) Knowledge-informed Pareto simulated annealing for multi-objective spatial allocation. Comput Environ Urban Syst 31(3):253-281. doi:10.1016/j.compenvurbsys.2006.08. 002

Eberhart R, Kennedy J (1995) A new optimizer using particle swarm theory. In: 6th international symposium on micro machine and human science. IEEE service center, Piscataway, NJ, Nagoya, Japan, pp 39-43

El Sayed Abdel Asís MH (2007) Parametric and multiobjective optimisation applied in agriculture: the study of cropping pattern in the Ameriya region in winter crops. Revista investigación operacional 28(1):17-24

Eldrandaly K (2010) A GEP-based spatial decision support system for multisite land use allocation. Appl Soft Comput 10(3):694-702. doi: 10.1016/j.asoc.2009.07.014

Farmer J, Packard N, Perelson A (1986) The immune system, adaptation, and machine learning. Physica D: Nonlinear Phenomena 22(1-3): 187-204. doi:10.1016/0167-2789(86)90240-X

Fotakis D, Sidiropoulos E (2012) A new multi-objective self-organizing optimization algorithm (MOSOA) for spatial optimization problems. Appl Math Comput 218(9):5168-5180. doi:10.1016/j.amc. 2011.11.003

Fotakis D, Sidiropoulos E (2014) Combined land-use and water allocation planning. Ann Oper Res 219(1):169-185. doi:10.1007/s10479012-1080-y

Gabriel SA, Faria JA, Moglen GE (2006) A multiobjective optimization approach to smart growth in land development. Socio Econ Plan Sci 40(3):212-248. doi:10.1016/j.seps.2005.02.001

Gao Q, Kang M, Xu H, Jiang Y, Yang J (2010) Optimization of land use structure and spatial pattern for the semi-arid loess hilly-gully region in China. CATENA 81(3):196-202. doi:10.1016/j.catena.2010.03. 002

Gärtner D, Keller A, Schulin R (2013) A simple regional downscaling approach for spatially distributing land use types for agricultural land. Agric Syst 120:10-19. doi:10.1016/j.agsy.2013.04.006

Georgiou PE, Papamichail DM (2008) Optimization model of an irrigation reservoir for water allocation and crop planning under various weather conditions. Irrig Sci 26(6):487-504. doi:10.1007/s00271008-0110-7

Glover F (1989) Tabu search—part I. ORSA J Comput 1(3):190-206. doi:10.1287/ijoc.1.3.190

Glover F (1990) Tabu search—part II. ORSA J Comput 2:4-32. doi:10. 1287/ijoc.2.1.4

Groot JCJ, Jellema A, Rossing WAH (2010) Designing a hedgerow network in a multifunctional agricultural landscape: balancing tradeoffs among ecological quality, landscape character and implementation costs. Eur J Agron 32(1):112-119. doi:10.1016/j.eja.2009.07. 002

Groot JCJ, Oomen GJM, Rossing WAH (2012) Multi-objective optimization and design of farming systems. Agric Syst 110:63-77. doi:10. 1016/j.agsy.2012.03.012

Groot JCJ, Rossing WAH, Jellema A, Stobbelaar DJ, Renting H, Van Ittersum MK (2007) Exploring multi-scale trade-offs between nature conservation, agricultural profits and landscape quality - a methodology to support discussions on land-use perspectives. Agric Ecosyst Environ 120(1):58-69. doi:10.1016/j.agee.2006.03.037
Handing W, Xin Y (2014) Corner sort for Pareto-based many-objective optimization. Cybern IEEE Trans 44(1):92-102. doi:10.1109/tcyb. 2013.2247594

He J, Chen T, Yao X (2014) On the easiest and hardest fitness functions. IEEE Trans Evol Comput 99:1. doi:10.1109/tevc.2014.2318025

He J, Reeves C, Witt C, Yao X (2007) A note on problem difficulty measures in black-Box optimization: classification, realizations and predictability. Evol Comput 15(4):435-443. doi:10.1162/evco. 2007.15.4.435

Holland JH (1975) Adaptation in natural and artificial systems. University of Michigan Press

Hooke RL, Martín Duque JF, Pedraza Gilsanz J (2012) Land transformation by humans: a review. GSA Today 22(12):4-10. doi:10.1130/ GSAT151A.1

Huang H (2010) Multi-objective particle swarm optimization for land use structure. In: Second International Conference on Computational Intelligence and Natural Computing Proceedings (CINC), 13-14 September, pp 217-220. doi: 10.1109/CINC.2010.5643853

Ishibuchi H, Tsukamoto N, Nojima Y (2008) Evolutionary manyobjective optimization: a short review. In: Evolutionary Computation, 2008. CEC 2008. (IEEE World Congress on Computational Intelligence). IEEE Congress on, 1-6 June 2008, pp 2419-2426. doi: 10.1109/CEC.2008.4631121

Janssen R, van Herwijnen M, Stewart TJ, Aerts JCJH (2008) Multiobjective decision support for land-use planning. Environ Plan B: Plan Des 35(4):740-756. doi:10.1068/b33071

Jarraya B, Bouri A (2012) Metaheuristic optimization backgrounds: a literature review. Int J Contemp Bus Stud 3(12):31-44

Jones DF, Mirrazavi SK, Tamiz M (2002) Multi-objective meta-heuristics: an overview of the current state-of-the-art. Eur J Oper Res 137(1):1-9. doi:10.1016/S0377-2217(01)00123-0

Kennedy J, Eberhart R (1995) Particle swarm optimization. In: Neural Networks, 1995. Proceedings., IEEE International Conference on, Perth, WA, Australia, IEEE, vol 1944, pp 1942-1948. doi: 10.1109/ ICNN.1995.488968

Kirkpatrick S, Gelatt CD, Vecchi MP (1983) Optimization by simulated annealing. Science 220(4598):671-680. doi:10.1126/science.220. 4598.671

Klein T, Holzkämper A, Calanca P, Seppelt R, Fuhrer J (2013) Adapting agricultural land management to climate change: a regional multiobjective optimization approach. Landscape Ecol:1-19. doi: 10. 1007/s10980-013-9939-0

Kollat JB, Reed PM (2006) Comparing state-of-the-art evolutionary multi-objective algorithms for long-term groundwater monitoring design. Adv Water Resour 29(6):792-807. doi:10.1016/j. advwatres.2005.07.010

Laporte G, Osman I (1995) Routing problems: a bibliography. Ann Oper Res 61(1):227-262. doi:10.1007/BF02098290

Le Ber F, Dury A, Chevrier V, Benoit M (eds) (1999) Simuler l'organisation spatiale d'un territoire agricole: différentes approches. Modèles et Systèmes Multi-Agents pour la Gestion de l'Environnement et des Territoires. Cemagref

Lehmann N, Finger R, Klein T, Calanca P, Walter A (2013) Adapting crop management practices to climate change: modeling optimal solutions at the field scale. Agric Syst 117:55-65. doi:10.1016/j. agsy.2012.12.011

Ligmann-Zielinska A, Church R, Jankowski P (2005) Sustainable urban land use allocation with spatial optimization In: The 8th International Conference on GeoComputation, University of Michigan, United States of America, 31 July - 3 August

Lin M-H, Tsai J-F, Yu C-S (2012) A review of deterministic optimization methods in engineering and management. Math Probl Eng 2012:15. doi:10.1155/2012/756023

Liu X, Ou J, Li X, Ai B (2013a) Combining system dynamics and hybrid particle swarm optimization for land use allocation. Ecol Model 257: 11-24. doi:10.1016/j.ecolmodel.2013.02.027 
Liu Y, Shen H, Yang W, Yang J (2013b) Optimization of agricultural BMPs using a parallel computing based multi-objective optimization algorithm. Int J Environ Resour Res 1(1):39-50

Liu Y, Tang D, Liu D, Kon X (2013c) A land use spatial allocation model based on ant colony optimization. Paper presented at the The 12th International Conference on GeoComputation LIESMARS, Wuhan University, Wuhan, China, 23 to 25 May, 2013

Loonen W, Heuberger PSC, Bakema AH, Schot P (2006) Application of a genetic algorithm to minimize agricultural nitrogen deposition in nature reserves. Agricultural Systems 88(2-3):360-375. doi:10. 1016/j.agsy.2005.06.021

Ma S, He J, Liu F, Yu Y (2011) Land-use spatial optimization based on PSO algorithm. Geo-Spat Inf Sci 14(1):54-61. doi:10.1007/s11806011-0437-8

Madhuri, Deep K (2009) A state-of-the-art review of population-based parallel meta-heuristics. In: Nature \& Biologically Inspired Computing, 2009. NaBIC 2009. World Congress on, 9-11, pp 1604-1607. doi: 10.1109/NABIC.2009.5393657

Masoomi Z, Mesgari MS, Hamrah M (2012) Allocation of urban land uses by multi-objective particle swarm optimization algorithm. Int $\mathrm{J}$ Geogr Inf Sci 27(3):542-566. doi:10.1080/13658816.2012.698016

Matthews KB (2001) Applying genetic algorithms to multi-objective land-use planning. The Robert Gordon University, Aberdeen

Matthews KB, Craw S, Elder S, Sibbald AR (2000) Evaluating multiobjective land use planning tools using soft systems methods. Paper presented at the 19th workshop of the UK Planning and Scheduling Special Interest Group (PLANSIG 2000), The Open University, Milton Keynes, England, 14-15 December, 2000

Matthews KB, Buchan K, Sibbald AR, Craw S (2002) Using softsystems methods to evaluate the outputs from multi-objective land use planning tools In: First biennial meeting of the International Environmental Modelling and Software Society, University of Lugano, Switzerland, pp 247-252

Matthews KB, Buchan K, Sibbald AR, Craw S (2006) Combining deliberative and computer-based methods for multi-objective land-use planning. Agric Syst 87(1):18-37. doi:10.1016/j.agsy.2004.11.002

Matthews KB, Sibbald AR, Craw S (1999) Implementation of a spatial decision support system for rural land use planning: integrating geographic information system and environmental models with search and optimisation algorithms. Comput Electron Agric 23(1):9-26. doi:10.1016/S0168-1699(99)00005-8

McRoberts N, Ververidis K, Barnes A (2009a) Agricultural Policy Optimiser (APolO): A new class of model for integrated analysis of multiple policy objectives. In: Integrated agricultural systems: methodologies, modelling and measuring Conference Edinburg, UK.,. ASPECTS OF APPLIED BIOLOGY, pp 173-176

McRoberts N, Ververidis K, Barnes A (2009b) Use of multivariate methods to summarise the results from an evolutionary policy optimisation model (APolO): A case study for Scottish agriculture. In: Integrated agricultural systems: methodologies, modelling and measuring Conference, Edinburg, UK., ASPECTS OF APPLIED BIOLOGY, pp 177-180

Meyer BC, Wolf T, Grabaum R (2012) A multifunctional assessment method for compromise optimisation of linear landscape elements. Ecol Indic 22:53-63. doi:10.1016/j.ecolind.2011.07.020

Min Q, Lijie P, Ming Z, Lingyan W (2010) Spatial optimization method for sustainable multiobjective land use allocation. In: 18th International Conference on Geoinformatics, pp 1-6. doi: 10.1109/ GEOINFORMATICS.2010.5567520

Morio M, Schädler S, Finkel M (2013) Applying a multi-criteria genetic algorithm framework for brownfield reuse optimization: improving redevelopment options based on stakeholder preferences. J Environ Manag 130:331-346. doi:10.1016/j.jenvman.2013.09.002

Moulton CM, Roberts SA, Calamai PH (2009) Hierarchical clustering of multiobjective optimization results to inform land-use decision making. URISA J 21(2):25-37
Mousa AA, El_Desoky IM (2013) Stability of Pareto optimal allocation of land reclamation by multistage decision-based multipheromone ant colony optimization. Swarm Evol Comput 13:13-21. doi:10. 1016/j.swevo.2013.06.003

Münier B, Birr-Pedersen K, Schou JS (2004) Combined ecological and economic modelling in agricultural land use scenarios. Ecol Model 174(1-2):5-18. doi:10.1016/j.ecolmodel.2003.12.040

Nanlin J, Termansen M, Hubacek K (2008) Genetic algorithms for dynamic land-use optimization. In: IEEE World Congress on Computational Intelligence, pp 3816-3821. doi: 10.1109/CEC. 2008.4631315

O'Callaghan JR (1995) NELUP: an introduction. J Environ Plan Manag 38(1):5-20. doi:10.1080/09640569513084

Ólafsson S (2006) Metaheuristics. In: Nelson, Henderson (eds) Handbook on Simulation, Handbooks in Operations Research and Management Science, vol VII. Elsevier, pp 633-654

Orsi F, Church RL, Geneletti D (2011) Restoring forest landscapes for biodiversity conservation and rural livelihoods: a spatial optimisation model. Environ Model Softw 26(12):1622-1638. doi:10.1016/ j.envsoft.2011.07.008

Ortega Álvarez J, de Juan VJ, Tarjuelo Martín-Benito J, López Mata E (2004) MOPECO: an economic optimization model for irrigation water management. Irrig Sci 23(2):61-75. doi:10.1007/s00271-0040094-x

Panagopoulos Y, Makropoulos C, Mimikou M (2013) Multi-objective optimization for diffuse pollution control at zero cost. Soil Use Manag 29:83-93. doi:10.1111/sum.12012

Pitzer E, Affenzeller M (2012) A comprehensive survey on fitness landscape analysis. In: Fodor J, Klempous R, Suárez Araujo C (eds) Recent Advances in Intelligent Engineering Systems, vol 378. Studies in Computational Intelligence. Springer Berlin, Heidelberg, pp 161-191. doi:10.1007/978-3-642-23229-9_8

Porta J, Parapar J, Doallo R, Rivera FF, Santé I, Crecente R (2013) High performance genetic algorithm for land use planning. Comput Environ Urban Syst 37:45-58. doi:10.1016/j.compenvurbsys. 2012.05.003

Prato T (2005) Modeling ecological impacts of landscape change. Environ Model Softw 20(10):1359-1363. doi:10.1016/j.envsoft. 2005.01.003

Qi H, Altinakar MS (2011) A conceptual framework of agricultural land use planning with BMP for integrated watershed management. J Environ Manag 92(1):149-155. doi:10.1016/j.jenvman.2010.08. 023

Rabotyagov S, Campbell T, Valcu A, Gassman P, Jha M, Schilling K, Wolter C, Kling C (2012) Spatial multiobjective optimization of agricultural conservation practices using a SWAT model and an evolutionary algorithm. J Vis Exp: JoVE 70:e4009. doi:10.3791/ 4009

Raggi M, Sardonini L, Viaggi D (2013) The effects of the common agricultural policy on exit strategies and land re-allocation. Land Use Policy 31:114-125. doi:10.1016/j.landusepol.2011.12.009

Rui W, Purshouse RC, Fleming PJ (2013) Preference-inspired coevolutionary algorithms for many-objective optimization. IEEE Trans Evol Comput 17(4):474-494. doi:10.1109/tevc.2012.2204264

Sadeghi SHR, Jalili K, Nikkami D (2009) Land use optimization in watershed scale. Land Use Policy 26(2):186-193. doi:10.1016/j. landusepol.2008.02.007

Santé-Riveira I, Boullón-Magán M, Crecente-Maseda R, Miranda-Barrós D (2008) Algorithm based on simulated annealing for land-use allocation. Comput Geosci 34(3):259-268. doi:10.1016/j.cageo.2007. 03.014

Sarkar S, Pressey RL, Faith DP, Margules CR, Fuller T, Stoms DM, Moffett A, Wilson KA, Williams KJ, Williams PH, Andelman S (2006) Biodiversity conservation planning tools: present status and challenges for the future. Ann Rev Environ Res 31. doi: 10.1146/ annurev.energy.31.042606.085844 
Sarttra T, Manokuakoon S, Horadee S, Choosakulwong K (2013) Application of dynamic programming to agricultural land allocation: case study Phutthamonthon District, Nakhon Pathom Province, Thailand. In: The International MultiConference of Engineers and Computer Scientists Hong Kong, pp 893-897

Seppelt R, Lautenbach S, Volk M (2013) Identifying trade-offs between ecosystem services, land use, and biodiversity: a plea for combining scenario analysis and optimization on different spatial scales. Curr Opin Environ Sustain 5(5):458-463. doi:10.1016/j.cosust.2013.05. 002

Seppelt R, Voinov A (2002) Optimization methodology for land use patterns using spatially explicit landscape models. Ecol Model 151(2-3):125-142. doi:10.1016/S0304-3800(01)00455-0

Seppelt R, Voinov A (2003) Optimization methodology for land use patterns - evaluation based on multiscale habitat pattern comparison. Ecol Model 168(3):217-231. doi:10.1016/S0304-3800(03) 00138-8

Sinha A, Deb K, Korhonen P, Wallenius J (2010) Progressively interactive evolutionary multi-objective optimization method using generalized polynomial value functions. In: Evolutionary Computation (CEC), 2010 I.E. Congress on, pp 1-8. doi:10.1109/cec.2010. 5586278

Stewart TJ, Janssen R, van Herwijnen M (2004) A genetic algorithm approach to multiobjective land use planning. Comput Oper Res 31(14):2293-2313. doi:10.1016/S0305-0548(03)00188-6

Store R, Kangas J (2001) Integrating spatial multi-criteria evaluation and expert knowledge for GIS-based habitat suitability modelling. Landsc Urban Plan 55(2):79-93. doi:10.1016/S0169-2046(01) 00120-7

Storn R, Price K (1997) Differential evolution - a simple and efficient heuristic for global optimization over continuous spaces. J Glob Optim 11(4):341-359. doi:10.1023/A:1008202821328

Taki H, Maeto K, Okabe K, Haruyama N (2013) Influences of the seminatural and natural matrix surrounding crop fields on aphid presence and aphid predator abundance within a complex landscape. Agric Ecosyst Environ 179:87-93. doi:10.1016/j.agee.2013.07.014

Tang K, Peng F, Chen G, Yao X (2014) Population-based algorithm portfolios with automated constituent algorithms selection. Inf Sci 279:94-104. doi:10.1016/j.ins.2014.03.105

Van Huylenbroeck G (1997) Multicriteria tools for the trade-off analysis in rural planning between economic and environmental objectives. Appl Math Comput 83(2-3):261-280. doi:10.1016/S00963003(96)00188-9

van Langevelde F, Claassen F, Schotman A (2002) Two strategies for conservation planning in human-dominated landscapes. Landsc Urban Plan 58(2-4):281-295. doi:10.1016/S0169-2046(01)00227-4

Ververidis KA (2008) A multi-objective bi-level optimisation model for agricultural policy in Scotland. University of Edinburgh, Scotland

Voss S, Osman IH, Roucairol C (1999) Meta-heuristics: advances and trends in local search paradigms for optimization. Kluwer Academic Publishers
Walangitan HD, Setiawan B, Tri Raharjo B, Polii B (2012) Optimization of land use and allocation to ensure sustainable agriculture in the catchment area of Lake Tondano, Minahasa, North Sulawesi, Indonesia. Int J Civ Environ Eng IJCEE-IJENS 12(3):68-75

Wang S-H, Huang S-L, Budd WW (2012) Integrated ecosystem model for simulating land use allocation. Ecol Model 227:46-55. doi:10. 1016/j.ecolmodel.2011.12.009

Wang X, Yu S, Huang GH (2004) Land allocation based on integrated GIS-optimization modeling at a watershed level. Landsc Urban Plan 66(2):61-74. doi:10.1016/S0169-2046(03)00095-1

Wankhade MO, Lunge HS (2012) Allocation of agricultural land to the major crops of saline track by linear programming approach: a case study. Int J Sc Technol Res 1(9):21-25

Wetter M, Wright J (2004) A comparison of deterministic and probabilistic optimization algorithms for nonsmooth simulation-based optimization. Build Environ 39(8):989-999. doi:10.1016/j.buildenv. 2004.01.022

Wossink A, van Wenum J, Jurgens C, de Snoo G (1999) Co-ordinating economic, behavioural and spatial aspects of wildlife preservation in agriculture. Eur Rev Agric Econ 26(4):443-460. doi:10.1093/erae/ 26.4.443

Xiao N, Bennett DA, Armstrong MP (2007) Interactive evolutionary approaches to multiobjective spatial decision making: a synthetic review. Comput Environ Urban Syst 31(3):232-252. doi:10.1016/ j.compenvurbsys.2006.08.001

Yang X-S (2011) Review of metaheuristics and generalised evolutionary walk algorithm. Int J Bio-Inspired Comput 3(2):77-84. doi:10.1504/ IJBIC.2011.039907

Yang X, Zheng X-Q, Lv L-N (2012) A spatiotemporal model of land use change based on ant colony optimization, Markov chain and cellular automata. Ecol Model 233:11-19. doi:10.1016/j.ecolmodel.2012. 03.011

Yao X, Xu Y (2006) Recent advances in evolutionary computation. J Comput Sci Technol 21(1):1-18. doi:10.1007/s11390-006-0001-4

Yu J, Chen Y, Wu J (2011) Modeling and implementation of classification rule discovery by ant colony optimisation for spatial land-use suitability assessment. Comput Environ Urban Syst 35(4):308-319. doi:10.1016/j.compenvurbsys.2010.12.003

Zhang J, Fu M, Zhang Z, Tao J, Fu W (2014) A trade-off approach of optimal land allocation between socio-economic development and ecological stability. Ecol Model 272:175-187. doi:10.1016/j. ecolmodel.2013.10.008

Zhang P, Liu Y, Pan Y, Yu Z (2013) Land use pattern optimization based on CLUE-S and SWAT models for agricultural non-point source pollution control. Math Comput Model 58(3-4):588-595. doi:10. 1016/j.mcm.2011.10.061

Zitzler E, Laumanns M, Thiele L (2001) SPEA2: improving the strength Pareto evolutionary algorithm. Eidgenössische Technische Hochschule Zürich (ETH). doi:10.3929/ethz-a-004284029 